\title{
Indicadores preliminares para avaliação da restauração em reflorestamentos de ambientes ciliares
}

\author{
Daniele Nogueira dos Reis ${ }^{1}$, Antonio Claudio Davide ${ }^{1}$, Daniel Furtado Ferreira ${ }^{2}$ \\ 'Universidade Federal de Lavras, Departamento de Ciências Florestais, Campus Universitário, CP 3037, CEP 37.200-000, Lavras, MG, Brasil \\ 2Universidade Federal de Lavras, Departamento de Ciências Exatas, Campus Universitário, CP 3037, CEP 37.200-000, Lavras, MG, Brasil
}

"Autor correspondente:

daniele.nog@gmail.com

Termos para indexação:

Áreas de preservação permanente

Função discriminante

Monitoramento

Index terms:

Permanent preservation areas

Discriminant function

Monitoring

Histórico do artigo:

Recebido em 31/7/2014

Aprovado em 16/12/2014

Publicado em 31/12/2014

doi: 10.4336/2014.pfb.34.80.757
Resumo - O sucesso da restauração em ecossistemas florestais pode ser avaliado pela seleção correta de indicadores que sejam representativos da consecução dos objetivos estabelecidos. A seleção pela técnica da análise discriminante consiste da separação e classificação de novas observações em grupos previamente definidos, reduzindo o número de variáveis, que são funções discriminantes linearmente dependentes das variáveis originais. O presente estudo objetiva definir um índice composto por atributos estruturais (número de espécies e indivíduos plantados, altura, área basal, número de espécies e indivíduos regenerantes) e atributos químicos do solo e pedológicos, para classificar reflorestamentos em ambientes ciliares, com relação à restauração tendo, como base, reflorestamento no entorno do reservatório da Usina Hidrelétrica de Volta Grande, MG. Onze variáveis foram utilizadas para a classificação prévia das parcelas nos grupos, como parcialmente restauradas ou não restauradas, e na análise discriminante realizada em seguida. As variáveis selecionadas pela função discriminante gerada foram: número de espécies e área basal dos indivíduos plantados, número de espécies e indivíduos regenerantes, acúmulo de serapilheira e capacidade de troca de cátions do solo. A compatibilidade de $98 \%$ entre a classificação prévia das parcelas e após a formação do índice demonstram a representatividade das variáveis selecionadas na avaliação da restauração dos reflorestamentos dos ambientes ciliares estudados.

\section{Preliminary indicators for restoration assessment in riparian reforestations}

\begin{abstract}
The restoration success in forest ecosystems can be adequately assessed by correct selection of indicators that represent the achievement of established goals. The discriminant analysis technique on indicators selection consists of separation and classification of new observations on pre-defined groups, reducing the number of variables that are discriminant functions linearly dependent of the original variables. This study aims to define an index composed by structural attributes (number of species and individuals planted, height, basal area, number of regenerant species and individuals) and chemical and pedological soil attributes to classify riparian reforested environments regarding to restoration taking as reference reforestation around the the Volta Grande reservoir, Minas Gerais State, Brazil. Eleven variables were used for previous classification of plots in partially restored or unrestored groups and also used for discriminant analysis. Variables selected by the discriminant function generated were: number of species and basal area of planted individuals, number of regenerant species and individuals, litter accumulation and soil cation exchange capacity. Compatibility of $98 \%$ from previous plot classifications and after index formation, show the representativeness of the selected variables on evaluation of restoration of riparian reforestations.
\end{abstract}




\section{Introdução}

A reformulação do Código Florestal Brasileiro, com a criação da lei que dispõe sobre a proteção da vegetação nativa (Lei 12.651 , de $25 / 05 / 2012$ ) e outras alterações propostas (Lei 12.727, de 17/10/2012) estabelecem a faixa mínima de vegetação de $30 \mathrm{~m}$ a $100 \mathrm{~m}$ em área rural, e $15 \mathrm{~m}$ a $30 \mathrm{~m}$ em área urbana (Brasil, 2012a; 2012b), para áreas situadas no entorno dos reservatórios artificiais destinados à geração de energia, consideradas áreas de preservação permanente (APP). Funções como estabilização das margens dos rios e proteção contra assoreamentos, habitat para a fauna silvestre, corredor ecológico entre fragmentos florestais e manutenção da qualidade e quantidade de água (Botelho \& Davide, 2002) justificam a importância da adequada restauração e conservação desses ecossistemas.

A adequada trajetória da restauração representa o restabelecimento, em longo prazo, das funções vitais do ecossistema (processos ecológicos), bem como da sua estrutura (diversidade de organismos) (Engel \& Parrota, 2008; Moraes et al., 2010). O recobrimento do solo pelo restabelecimento da regeneração natural (Melo \& Durigan, 2007; Ferreira et al., 2010), a eliminação de espécies invasoras (Isernhagen et al., 2009), a ciclagem de nutrientes (Aronson et al., 1993), a presença da fauna e agentes polinizadores (Andersen \& Sparling, 1997; Lomov et al., 2006), o curso da dinâmica sucessional e o incremento da biodiversidade (Aronson et al., 1993; Society for Ecological Restoration, 2004; Brancalion et al., 2009) são fatores que podem atuar como indicadores do progresso estrutural e funcional das áreas.

O conhecimento a respeito do monitoramento de áreas restauradas, por diferentes categorias de interessados (proprietários, órgãos ambientais, empresas privadas, sociedade) (Almeida \& Sanchez, 2005) está relacionado ao sucesso da prática implantada, e que pode servir como referencial para futuros projetos. Para isso é imprescindível que ocorram avanços na definição de indicadores de monitoramento de áreas com diferentes idades e métodos de restauração (Melo et al., 2007), considerando-se características relacionadas às especificidades de cada ecossistema, seu histórico de degradação e mesmo com o entendimento de que não existe uma fórmula pré estabelecida na restauração de ecossistemas (Ehrenfeld, 2000; Durigan et al., 2010; Moraes et al., 2010).
A complexidade dos ecossistemas e a diversidade de variáveis existentes influenciam a escolha de indicadores, principalmente porque os objetivos da recuperação, no sentido da restauração de ecossistemas superam os ideais iniciais de aporte de biomassa, rápido recobrimento do solo e desenvolvimento em altura e diâmetro, "indicadores" comumente adotados em florestas comerciais (Poggiani et al., 1998). Questionamentos com relação ao número mínimo de variáveis a serem empregadas, a periodicidade e o tempo de monitoramento necessário para afirmar que determinada área se encontra restaurada e também a flexibilidade dessas variáveis, para o emprego em diferentes áreas ou biomas justificam a continuidade de estudos sobre esse tema.

O presente estudo foi realizado com o objetivo de propor uma função (índice) composto por atributos estruturais da vegetação e atributos do solo que permita classificar reflorestamentos realizados em ambientes ciliares e com diferentes idades, com relação à restauração.

\section{Material e métodos}

\section{Localização e seleção de áreas}

As áreas avaliadas localizam-se nos municípios de Água Comprida (20³'19,32”S e 486'33,69”W) no Estado de Minas Gerais, Igarapava (20'2'17,69"S e $\left.47^{\circ} 44^{\prime} 52,49^{\prime \prime} \mathrm{W}\right)$ e Miguelópolis $\left(20^{\circ} 10^{\prime} 39,66^{\prime \prime} \mathrm{S}\right.$ e $48^{\circ} 2^{\prime} 0,45^{\prime}$ 'W), no Estado de São Paulo, Brasil, e representam reflorestamentos ciliares que margeiam o reservatório da Usina Hidrelétrica (UHE) de Volta Grande (região do Baixo Rio Grande), iniciados a partir de convênio estabelecido entre a Companhia Energética de Minas Gerais - CEMIG e os proprietários rurais para o reflorestamento das áreas abrangidas pelo reservatório (Figura 1).

As áreas no entorno do reservatório da UHE de Volta Grande apresentam altitude média de $500 \mathrm{~m}$. O solo predominante é do tipo latossolo vermelho distroférrico (IBGE, 2001). Pela classificação de Köppen o clima da região é do tipo Awa - tropical, de verões quentes chuvosos e invernos secos. As formações florestais naturais são remanescentes de Floresta Estacional Semidecidual Submontana nas partes mais altas e bem drenadas e Floresta Estacional Semidecidual Aluvial, nas partes mais baixas, adjacentes aos cursos d'água e periodicamente inundáveis (IBGE, 2002). 

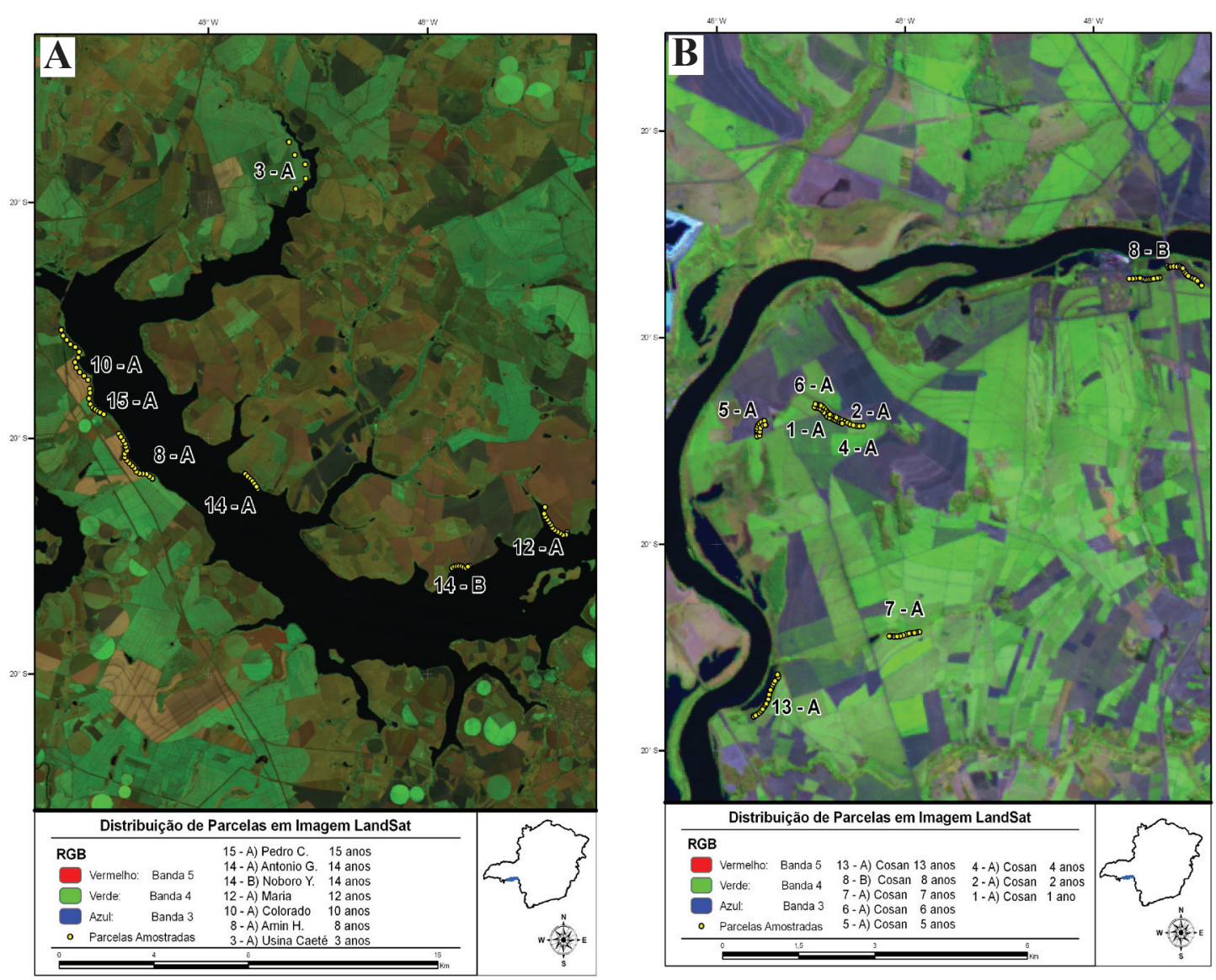

Figura 1. Localização dos reflorestamentos ciliares nas margens do reservatório de Volta Grande, nos Municípios de Água Comprida e Miguelópolis (A) e em tributários do Rio Grande, no Município de Igarapava (B).

Os reflorestamentos selecionados para avaliação foram amostrados com o objetivo de englobar todas as faixas de idade de plantio existentes. Dentre as 87 áreas ciliares reflorestadas $(488,50$ ha) pela CEMIG, no período de 1992 a 2007, 15 reflorestamentos com idades variando de um a 15 anos foram selecionados, correspondendo a uma área total amostrada de 49,12 ha. O uso prévio dos reflorestamentos, bem como o uso atual das áreas adjacentes a estes são descritos na Tabela 1 .

\section{Avaliação dos plantios}

Os plantios foram avaliados pelo estabelecimento de transectos com largura de $10 \mathrm{~m}$ e comprimento variável de acordo com a extensão da faixa de plantio de cada área estudada e o número de transectos (intensidade amostral), distribuídos de forma sistematizada, variou com a área total dos reflorestamentos (Tabela 1). Em cada área, a cada $10 \mathrm{~m}$ no sentido do aclive foram divididos os transectos, originando parcelas de $10 \mathrm{~m} \times 10 \mathrm{~m} \mathrm{e}$, ao final de cada parcela, subparcelas de
$20 \mathrm{~m}^{2}(2 \mathrm{~m} \times 10 \mathrm{~m})$ foram alocadas para amostragem da regeneração natural.

No estrato arbóreo todos os indivíduos com circunferência à altura do peito $(\mathrm{CAP}) \geq 15 \mathrm{~cm}$ foram identificados, sendo mensurada a altura $(\mathrm{m})$ e o CAP $(\mathrm{cm})$. No estrato regenerante, indivíduos com altura $>10 \mathrm{~cm}$ e $\mathrm{CAP}<15 \mathrm{~cm}$ foram identificados, com medição da altura $(\mathrm{cm})$. O CAP foi medido com o auxílio de fita métrica e a altura mensurada com o uso de vara graduada. As espécies foram classificadas nas famílias reconhecidas pelo sistema do Angiosperm Phylogeny Group III (2009).

No centro de cada sub-parcela da regeneração natural foi coletada uma amostra de serapilheira, com o auxílio de um quadro de metal, com as dimensões de $25 \mathrm{~cm} \times$ $25 \mathrm{~cm}$. O número de amostras coletadas variou com o número de parcelas estabelecidas por área (Tabela 1). As amostras coletadas foram acondicionadas em sacos plásticos e identificadas para posterior quantificação do acúmulo de serapilheira. 
Tabela 1. Caracterização geral dos reflorestamentos ciliares avaliados.

\begin{tabular}{|c|c|c|c|c|c|c|}
\hline Legenda & $\begin{array}{l}\text { Idade } \\
\text { (anos) }\end{array}$ & $\begin{array}{c}\text { Área amostrada (ha)/ } \\
\text { Intensidade amostral } \\
(\%)\end{array}$ & $\begin{array}{c}\text { Parcelas e } \\
\text { dimensões (m) }\end{array}$ & $\begin{array}{c}\text { Espaçamento no } \\
\text { plantio } \\
\text { (m) }\end{array}$ & Uso prévio & Área adjacente \\
\hline $15 \mathrm{~A}$ & 15 & $1,30 / 10$ & $4(10 \times 19,0)$ & $2 \times 2$ & Pastagem & Pastagem \\
\hline $14 \mathrm{~A}$ & 14 & $2,30 / 8$ & $8(10 \times 18,5)$ & $3 \times 1,5$ & Pastagem & Pastagem \\
\hline 14B & 14 & $2,40 / 8$ & $6(10 \times 23,6)$ & $3 \times 1,5$ & Cereais & Seringal \\
\hline $13 \mathrm{~A}$ & 13 & $9,15 / 5$ & $5(10 \times 98,6)$ & $3 \times 2$ & Cana-de-açúcar & Cana-de-açúcar \\
\hline $12 \mathrm{~A}$ & 12 & $4,20 / 8$ & $11(10 \times 20,7)$ & $3 \times 2$ & Pastagem & Pastagem \\
\hline $10 \mathrm{~A}$ & 10 & $11,70 / 4$ & $17(10 \times 15,6)$ & $3 \times 2$ & Cana-de-açúcar & Cana-de-açúcar \\
\hline $8 \mathrm{~A}$ & 8 & $7,50 / 7$ & $17(10 \times 16,5)$ & $3 \times 2$ & Cana-de-açúcar & Cana-de-açúcar \\
\hline $8 \mathrm{~B}$ & 8 & $2,50 / 8$ & $2(10 \times 93,0)$ & $3 \times 2$ & Cana-de-açúcar & Cana-de-açúcar \\
\hline $7 \mathrm{~A}$ & 7 & $0,85 / 10$ & $6(10 \times 13,5)$ & $3 \times 2$ & Cana-de-açúcar & Cana-de-açúcar \\
\hline $6 \mathrm{~A}$ & 6 & $0,54 / 10$ & $3(10 \times 20,4)$ & $3 \times 2$ & Cana-de-açúcar & Cana-de-açúcar \\
\hline $5 \mathrm{~A}$ & 5 & $0,84 / 10$ & $3(10 \times 25,2)$ & $3 \times 2$ & Cana-de-açúcar & Cana-de-açúcar \\
\hline $4 \mathrm{~A}$ & 4 & $0,60 / 10$ & $3(10 \times 27,6)$ & $3 \times 2$ & Cana-de-açúcar & Cana-de-açúcar \\
\hline $3 \mathrm{~A}$ & 3 & $3,08 / 8$ & $5(10 \times 70,7)$ & $3 \times 3$ & Cana-de-açúcar & Cana-de-açúcar \\
\hline $2 \mathrm{~A}$ & 2 & $1,60 / 10$ & $6(10 \times 23,0)$ & $3 \times 2$ & Cana-de-açúcar & Cana-de-açúcar \\
\hline $1 \mathrm{~A}$ & 1 & $0,56 / 10$ & $3(10 \times 23,0)$ & $3 \times 2$ & Cana-de-açúcar & Cana-de-açúcar \\
\hline
\end{tabular}

Foi realizada uma única coleta da serapilheira na mesma época do ano (estação seca - julho) para todas as áreas reflorestadas. Inicialmente, para cada amostra foi registrado o peso úmido em balança analítica (precisão de $0,001 \mathrm{~g}$ ). As amostras foram acondicionadas em sacos de papel e levadas para a secagem em estufa, sob temperatura de $55^{\circ} \mathrm{C}$, até atingirem peso constante, para a determinação da massa seca em $\mathrm{Mg} \mathrm{ha}^{-1}$. Nas áreas 3A, 2A e 1A não foram coletadas amostras de serapilheira em virtude da realização de tratos culturais recentes (capina manual).

No mesmo local de coleta da serapilheira procedeuse a coleta de amostras de solo na profundidade de 0 a $20 \mathrm{~cm}$, com auxílio de um trado tipo holandês e o número de amostras coletadas (amostra composta) foi variável com o número de parcelas estabelecidas para avaliação do estrato arbóreo (Tabela 1). Na análise química, foram determinados os seguintes atributos, segundo protocolo da Empresa Brasileira de Pesquisa Agropecuária - EMBRAPA (Claessen, 1997): pH em água; teores de potássio $(\mathrm{K})$, fósforo $(\mathrm{P})$, cálcio $(\mathrm{Ca})$, magnésio $(\mathrm{Mg})$ e alumínio $(\mathrm{Al})$, acidez potencial $(\mathrm{H}+$ $\mathrm{Al}$ ), soma de bases (SB), capacidade de troca de cátions ou CTC efetiva (t), CTC a pH 7,0 (T), saturação por alumínio (m), saturação por bases (V), matéria orgânica (MO), além da determinação dos teores de silte, areia e argila (análise textural).

\section{Análise dos dados}

Após a coleta e o processamento dos dados, foi realizada análise estatística descritiva (média e desvio padrão) para todas as variáveis nos plantios avaliados. Das 23 variáveis, incluindo a estrutura da vegetação e características químicas e texturais do solo obtidas nas avaliações dos reflorestamentos do ponto de vista ecológico, foram selecionadas 11 consideradas representativas por consultas a trabalhos relacionados a indicadores de avaliação e monitoramento de reflorestamentos (Souza \& Batista, 2004; Gandolfi, 2006; Melo \& Durigan, 2007 ).

As variáveis selecionadas para o emprego da análise discriminante foram: número de espécies plantadas encontradas na avaliação $\left(\mathrm{X}_{1}\right)$, densidade de indivíduos plantados por hectare $\left(\mathrm{X}_{2}\right)$, altura média dos indivíduos plantados $\left(\mathrm{X}_{3}\right)$, área basal dos indivíduos plantados $\left(\mathrm{X}_{4}\right)$, número de espécies regenerantes $\left(\mathrm{X}_{5}\right)$, densidade de indivíduos regenerantes por hectare $\left(\mathrm{X}_{6}\right)$, acúmulo de serapilheira $\left(\mathrm{X}_{7}\right), \mathrm{pH}$ do solo $\left(\mathrm{X}_{8}\right)$, soma de bases do solo $\left(\mathrm{X}_{9}\right)$, CTC do solo $\left(\mathrm{X}_{10}\right)$ e matéria orgânica do solo $\left(\mathrm{X}_{11}\right)$.

A técnica de análise discriminante separa conjuntos distintos de objetos (observações) e fixa (aloca) novos objetos em conjuntos ou grupos previamente definidos considerando-se suas características gerais (Mingoti, 2007; Ferreira, 2008), reduzindo o número de variáveis, que são funções discriminantes linearmente dependentes das variáveis originais (Scheeren et al., 2000). 
$\mathrm{Na}$ ausência de remanescentes próximos às áreas de estudo, o reflorestamento ou sítio mais conservado, quando comparado a sítios nos quais houve distúrbios (Moraes et al., 2010), no caso o sítio 14B, foi adotado como área de referência. Com isso, os valores médios das variáveis estruturais e dos atributos de solo dessa área constituíram-se nos valores de referência, possuindo o valor máximo técnico (10), em um sistema de pontuação variando de 1 a 10 .

Em seguida foi realizada a classificação prévia das parcelas das áreas em parcialmente restauradas ou não restauradas. As notas atribuídas às 11 variáveis das parcelas dos reflorestamentos foram calculadas pelo estabelecimento de proporcionalidade, com os valores de notas máximas da área de referência selecionada. A cada uma das variáveis foi atribuído um peso representativo da sua importância no processo de restauração de áreas, por meio da discussão entre profissionais da área de silvicultura e fertilidade do solo.

Em cada parcela, a nota final para cada atributo foi formada pelo produto do seu valor calculado (em relação aos valores de referência da área 14B) e o peso atribuído à variável considerada. $\mathrm{O}$ valor total, ou escore, correspondeu ao somatório de todas as variáveis em uma parcela multiplicadas pelos respectivos pesos das variáveis (escore da área de referência: 200). A parcela foi classificada como parcialmente restaurada (Grupo 2) quando apresentou valor do escore superior a $80 \%$ (escore > 180) do valor total máximo. Caso contrário, essa foi alocada no Grupo 1, representando parcelas não restauradas.

O valor do escore adotado para a classificação das parcelas em parcialmente restauradas ou não restauradas foi arbitrariamente definido. Considerando-se que a área de referência é um reflorestamento que ainda se encontra em processo de restauração, caso as variáveis das parcelas atingissem, no mínimo $80 \%$ dos valores da área referência, essa poderia ser classificada como parcialmente restaurada. A classificação prévia efetuada para as 99 parcelas que compõem os reflorestamentos avaliados foi utilizada para a futura comparação dessa com a classificação originada pela função discriminante gerada. Na Tabela 2 é apresentado o procedimento de cálculo para a classificação prévia das parcelas dos reflorestamentos avaliados.

A análise discriminante foi realizada em seguida, com os valores reais (valores obtidos em campo e/ou valores processados após a avaliação em campo) das 11 variáveis pré-selecionadas. O critério adotado, para a inclusão da variável na função discriminante gerada, foi o de que com a retirada dessa variável haveria o aumento do erro de classificação (nos grupos) a valores superiores a $5 \%$. A análise discriminante foi realizada pelo programa computacional Statistical Analysis System (SAS) versão 8.10 (SAS Institute, 1999).

Tabela 2. Exemplo do procedimento descrito para a classificação prévia das parcelas dos reflorestamentos, onde: parc. restaurada: parcialmente restaurada.

\begin{tabular}{|c|c|c|c|c|c|c|c|c|c|c|c|c|}
\hline $\begin{array}{l}\text { Área 14B } \\
\text { (referência) }\end{array}$ & $\mathbf{X}_{1}$ & $X_{2}$ & $\mathbf{X}_{3}$ & $\mathbf{X}_{4}$ & $X_{5}$ & $X_{6}$ & $\mathbf{X}_{7}$ & $X_{8}$ & $\mathbf{X}_{9}$ & $X_{10}$ & $\mathbf{X}_{11}$ & $\begin{array}{c}\text { Escore/ } \\
\text { Classificação }\end{array}$ \\
\hline $\begin{array}{l}\text { Valores } \\
\text { campo }\end{array}$ & 14 & 1.170 & 7,98 & 24,1 & 13 & 12.325 & 10,92 & 5,8 & 6,5 & 6,6 & 3,8 & \\
\hline $\begin{array}{l}\text { Pontuação } \\
(1 \text { a 10) }\end{array}$ & 10 & 10 & 10 & 10 & 10 & 10 & 10 & 10 & 10 & 10 & 10 & \\
\hline Peso & 2 & 1 & 1 & 2 & 3 & 1 & 2 & 1 & 2 & 2 & 3 & \\
\hline Valor final & 20 & 10 & 10 & 20 & 30 & 10 & 20 & 10 & 20 & 20 & 30 & $\begin{array}{l}>180 \text { Parc. restaurada; } \\
<180 \text { não restaurada }\end{array}$ \\
\hline $\begin{array}{c}\text { Área 10A } \\
\text { Parc. 11 } \\
\end{array}$ & $\mathbf{X}_{1}$ & $\mathbf{X}_{2}$ & $\mathbf{X}_{3}$ & $\mathbf{X}_{4}$ & $X_{5}$ & $X_{6}$ & $\mathbf{X}_{7}$ & $\mathbf{X}_{8}$ & $\mathbf{X}_{9}$ & $X_{10}$ & $\mathbf{X}_{11}$ & $\begin{array}{c}\text { Escore/ } \\
\text { Classificação } \\
\end{array}$ \\
\hline $\begin{array}{l}\text { Valores } \\
\text { campo }\end{array}$ & 14 & 1.000 & 7,5 & 28,6 & 5 & 9.750 & 10,63 & 5,6 & 7,0 & 7,2 & 3,0 & \\
\hline Pontuação & 10,4 & 8,5 & 9,4 & 11,8 & 4 & 7,91 & 9,7 & 9,7 & 10,8 & 10,9 & 7,96 & \\
\hline Peso & 2 & 1 & 1 & 2 & 3 & 1 & 2 & 1 & 2 & 2 & 3 & \\
\hline Valor final & 20,8 & 8,5 & 9,4 & 23,6 & 12 & 7,91 & 19,4 & 9,7 & 21,6 & 21,8 & 23,8 & $182,2 /$ Parc. restaurada \\
\hline
\end{tabular}




\section{Resultados e discussão}

Os valores médios das variáveis avaliadas nos reflorestamentos e os resultados da pré-classificação das parcelas e a classificação final, obtida pela função discriminante gerada são apresentados nas Tabelas 3 e 4.

As parcelas 2A-5 e 10A-12 na pré-classificação foram consideradas como parcialmente restaurada $\mathrm{e}$ não restaurada, respectivamente (Tabela 4). A área " $2 \mathrm{~A}$ " trata-se de um plantio recente, no qual as variáveis serapilheira, número de espécies e número de indivíduos regenerantes tiveram valores nulos, sendo as variáveis soma de bases (SB) e capacidade de troca catiônica (CTC) as que contribuíram para a pré-classificação da parcela como parcialmente restaurada. No entanto, pela função discriminante gerada, esta foi classificada como não restaurada. Para a parcela 12 da área "10A", o reduzido número de espécies e indivíduos regenerantes, quando comparados aos valores da área de referência ocasionou sua pré-classificação como não restaurada, mas a função discriminante gerada e os valores das variáveis químicas do solo: SB, CTC e matéria orgânica permitiram classificá-la como parcialmente restaurada.

Tabela 3. Valores médios das variáveis avaliadas nos reflorestamentos ciliares na UHE Volta Grande.

\begin{tabular}{|c|c|c|c|c|c|c|c|c|c|c|c|c|}
\hline Área & Parcela & $X_{1}$ & $\mathrm{X}_{2}$ & $X_{3}$ & $X_{4}$ & $X_{5}$ & $X_{6}$ & $\mathbf{X}_{7}$ & $\mathrm{X}_{8}$ & $X_{9}$ & $X_{10}$ & $X_{11}$ \\
\hline $15 \mathrm{~A}$ & 1 & 8 & 1.150 & 6,5 & 33,7 & 2 & 750 & 11,62 & 5,4 & 5,4 & 5,4 & 3,1 \\
\hline $15 \mathrm{~A}$ & 2 & 9 & 1.050 & 7,0 & 12,4 & 3 & 1.750 & 13,24 & 5,7 & 6,1 & 6,1 & 2,1 \\
\hline $15 \mathrm{~A}$ & 3 & 7 & 750 & 9,4 & 20,5 & 3 & 2.000 & 20,09 & 5,7 & 7,3 & 7,3 & 3,8 \\
\hline $15 \mathrm{~A}$ & 4 & 10 & 1.250 & 8,6 & 26,4 & 4 & 4.500 & 8,86 & 5,5 & 6,1 & 6,1 & 2,9 \\
\hline $14 \mathrm{~A}$ & 1 & 6 & 1.081 & 11,5 & 53,2 & 2 & 1.750 & 12,28 & 5,6 & 6,9 & 6,9 & 4,0 \\
\hline $14 \mathrm{~A}$ & 2 & 13 & 1.243 & 8,7 & 34,6 & 5 & 4.333 & 7,45 & 5,7 & 4,7 & 4,7 & 3,1 \\
\hline $14 \mathrm{~A}$ & 3 & 12 & 1.027 & 7,8 & 43,9 & 3 & 4.750 & 6,86 & 5,9 & 7,1 & 7,1 & 4,4 \\
\hline $14 \mathrm{~A}$ & 4 & 14 & 1.135 & 8,6 & 48,2 & 3 & 2.500 & 11,30 & 6,3 & 7,8 & 7,8 & 3,7 \\
\hline $14 \mathrm{~A}$ & 5 & 9 & 811 & 12,2 & 43,5 & 4 & 1.750 & 10,99 & 6,2 & 10,9 & 10,9 & 4,9 \\
\hline $14 \mathrm{~A}$ & 6 & 11 & 1.189 & 8,0 & 35,8 & 6 & 4.000 & 6,19 & 6,0 & 7,7 & 7,7 & 4,6 \\
\hline $14 \mathrm{~A}$ & 7 & 12 & 1.135 & 6,6 & 31,6 & 3 & 2.000 & 8,96 & 6,3 & 10,3 & 10,3 & 4,8 \\
\hline $14 \mathrm{~A}$ & 8 & 11 & 1.568 & 8,2 & 56,1 & 2 & 1.500 & 12,53 & 6,0 & 10,3 & 10,3 & 4,4 \\
\hline $14 \mathrm{~B}$ & 1 & 12 & 1.208 & 6,7 & 21,2 & 11 & 10.750 & 13,39 & 5,9 & 7,7 & 7,7 & 4,3 \\
\hline $14 \mathrm{~B}$ & 2 & 10 & 758 & 8,8 & 28,2 & 14 & 14.200 & 5,62 & 5,7 & 6,8 & 6,8 & 3,8 \\
\hline $14 \mathrm{~B}$ & 3 & 13 & 833 & 6,2 & 15,5 & 15 & 13.500 & 9,56 & 5,9 & 5,9 & 5,9 & 2,6 \\
\hline $14 \mathrm{~B}$ & 4 & 14 & 1.000 & 8,4 & 26,6 & 11 & 12.000 & 15,88 & 5,9 & 7,0 & 7,0 & 4,3 \\
\hline 14B & 5 & 20 & 1.593 & 9,7 & 34,0 & 9 & 10.000 & 11,50 & 5,7 & 5,9 & 6,1 & 3,8 \\
\hline 14B & 6 & 12 & 1.625 & 8,1 & 18,9 & 15 & 13.500 & 9,54 & 5,4 & 5,6 & 5,8 & 3,8 \\
\hline $13 \mathrm{~A}$ & 1 & 21 & 1.146 & 8,3 & 15,9 & 8 & 4.125 & 10,41 & 5,9 & 6,0 & 6,0 & 3,3 \\
\hline $13 \mathrm{~A}$ & 2 & 16 & 751 & 10,0 & 16,0 & 13 & 5.688 & 7,94 & 5,9 & 6,0 & 6,0 & 3,0 \\
\hline $13 \mathrm{~A}$ & 3 & 20 & 903 & 8,3 & 13,3 & 11 & 3.563 & 9,81 & 6,0 & 7,4 & 7,4 & 2,9 \\
\hline $13 \mathrm{~A}$ & 4 & 23 & 1.014 & 8,5 & 14,2 & 15 & 7.563 & 8,03 & 6,1 & 7,5 & 7,5 & 3,0 \\
\hline $13 \mathrm{~A}$ & 5 & 17 & 771 & 9,8 & 13,9 & 13 & 4.611 & 8,24 & 6,1 & 10,4 & 10,4 & 3,4 \\
\hline $12 \mathrm{~A}$ & 1 & 5 & 580 & 12,3 & 64,6 & 4 & 2.250 & 8,36 & 6,2 & 7,7 & 7,7 & 4,0 \\
\hline $12 \mathrm{~A}$ & 2 & 8 & 676 & 8,6 & 33,6 & 6 & 6.500 & 5,07 & 5,8 & 8,0 & 8,0 & 4,9 \\
\hline $12 \mathrm{~A}$ & 3 & 11 & 773 & 8,7 & 25,3 & 3 & 2.500 & 16,28 & 6,0 & 9,7 & 9,7 & 5,3 \\
\hline $12 \mathrm{~A}$ & 4 & 8 & 918 & 10,6 & 38,9 & 5 & 6.000 & 10,42 & 6,0 & 7,3 & 7,3 & 4,9 \\
\hline
\end{tabular}

$\mathrm{X}_{1}$ : número médio de espécies encontradas, avaliadas no plantio; $\mathrm{X}_{2}$ : número médio de indivíduos avaliados no plantio, por hectare; $\mathrm{X}_{3}$ : altura média das arvores com DAP $>5 \mathrm{~cm} ; \mathrm{X}_{4}$ : area basal média dos indivíduos com DAP $>5 \mathrm{~cm} ; \mathrm{X}_{5}$ : número médio de espécies regenerantes avaliadas no plantio; $\mathrm{X}_{6}$ : número médio de indivíduos regenerantes avaliados por plantio, por hectare; $\mathrm{X}_{7}$ : acúmulo de serapilheira, em $\mathrm{Mg}^{-1}$; $\mathrm{X}_{8}$ : potencial hidrogeniônico do solo $(\mathrm{pH}) ; \mathrm{X}_{9}$ : soma de bases dos solos $(\mathrm{SB}=\mathrm{Ca}+\mathrm{Mg}+\mathrm{K}+\mathrm{Na})$, em cmolc $\mathrm{dm}^{-3} ; \mathrm{X}_{10}$ : capacidade de troca catiônica do solo $(\mathrm{CTC})$, em $\mathrm{cmolc} \mathrm{DM}{ }^{-3} ; \mathrm{X}_{11}$ : matéria orgânica do solo, em dag $\mathrm{kg}^{-1}$. 
Tabela 3. Continuação.

\begin{tabular}{|c|c|c|c|c|c|c|c|c|c|c|c|c|}
\hline Área & Parcela & $\mathrm{X}_{1}$ & $X_{2}$ & $\mathbf{X}_{3}$ & $\mathbf{X}_{4}$ & $X_{5}$ & $X_{6}$ & $\mathbf{X}_{7}$ & $\mathrm{X}_{8}$ & $X_{9}$ & $X_{10}$ & $X_{11}$ \\
\hline $12 \mathrm{~A}$ & 5 & 9 & 1.063 & 8,3 & 17,1 & 2 & 750 & 7,38 & 5,8 & 7,3 & 7,3 & 4,8 \\
\hline $12 \mathrm{~A}$ & 6 & 13 & 1.256 & 7,8 & 47,3 & 5 & 1833 & 4,86 & 5,8 & 6,7 & 6,7 & 4,0 \\
\hline $12 \mathrm{~A}$ & 7 & 12 & 1.546 & 8,1 & 39,6 & 5 & 3.750 & 6,69 & 6,0 & 6,5 & 6,5 & 4,1 \\
\hline $12 \mathrm{~A}$ & 8 & 11 & 1.063 & 9,5 & 29,3 & 4 & 2.833 & 10,35 & 5,5 & 6,2 & 6,2 & 4,4 \\
\hline $12 \mathrm{~A}$ & 9 & 4 & 290 & 7,8 & 8,7 & 2 & 3.000 & 10,24 & 6,3 & 8,6 & 8,6 & 4,4 \\
\hline $12 \mathrm{~A}$ & 10 & 8 & 531 & 10,5 & 23,4 & 2 & 333 & 6,76 & 5,4 & 3,6 & 4,1 & 4,1 \\
\hline $12 \mathrm{~A}$ & 11 & 4 & 290 & 10,7 & 20,2 & 2 & 1.250 & 6,82 & 5,1 & 3,8 & 4,3 & 4,1 \\
\hline $10 \mathrm{~A}$ & 1 & 10 & 667 & 6,5 & 10,4 & 11 & 5.167 & 8,04 & 5,5 & 6,6 & 6,8 & 2,7 \\
\hline $10 \mathrm{~A}$ & 2 & 11 & 833 & 6,4 & 8,1 & 7 & 3.250 & 5,96 & 5,6 & 9,4 & 9,4 & 2,9 \\
\hline $10 \mathrm{~A}$ & 3 & 11 & 952 & 6,6 & 10,3 & 5 & 1.500 & 8,02 & 5,7 & 12,4 & 12,4 & 3,6 \\
\hline $10 \mathrm{~A}$ & 4 & 14 & 1.190 & 5,9 & 13,6 & 10 & 6.000 & 8,05 & 5,5 & 10,4 & 10,4 & 4,1 \\
\hline $10 \mathrm{~A}$ & 5 & 12 & 1.042 & 7,0 & 16,5 & 4 & 3.000 & 16,86 & 5,5 & 7,1 & 7,1 & 3,4 \\
\hline $10 \mathrm{~A}$ & 6 & 9 & 1.000 & 7,2 & 17,3 & 9 & 7.500 & 5,95 & 5,7 & 6,8 & 6,8 & 3,1 \\
\hline $10 \mathrm{~A}$ & 7 & 10 & 1.133 & 7,1 & 14,2 & 4 & 1.500 & 8,19 & 5,6 & 8,4 & 8,4 & 3,6 \\
\hline $10 \mathrm{~A}$ & 8 & 8 & 667 & 7,3 & 9,2 & 3 & 1.250 & 9,17 & 5,4 & 4,7 & 5,0 & 2,7 \\
\hline $10 \mathrm{~A}$ & 9 & 9 & 1.000 & 8,3 & 28,3 & 4 & 1.750 & 16,96 & 5,7 & 7,3 & 7,3 & 3,1 \\
\hline $10 \mathrm{~A}$ & 10 & 7 & 667 & 7,9 & 12,2 & 5 & 11.000 & 16,03 & 5,6 & 7,3 & 7,5 & 3,4 \\
\hline $10 \mathrm{~A}$ & 11 & 14 & 1.000 & 7,5 & 28,6 & 5 & 9750 & 10,63 & 5,6 & 7,0 & 7,2 & 3,0 \\
\hline $10 \mathrm{~A}$ & 12 & 12 & 905 & 8,0 & 16,5 & 3 & 5.750 & 8,64 & 5,6 & 7,6 & 7,6 & 4,6 \\
\hline $10 \mathrm{~A}$ & 13 & 9 & 733 & 9,1 & 17,2 & 4 & 13.500 & 10,41 & 5,8 & 9,3 & 9,3 & 3,1 \\
\hline $10 \mathrm{~A}$ & 14 & 5 & 1.167 & 12,0 & 48,8 & 1 & 1.500 & 18,18 & 5,6 & 7,3 & 7,5 & 3,8 \\
\hline $10 \mathrm{~A}$ & 15 & 3 & 667 & 13,3 & 44,7 & 3 & 1.500 & 11,95 & 5,2 & 7,5 & 7,8 & 4,6 \\
\hline $10 \mathrm{~A}$ & 16 & 4 & 1.000 & 14,7 & 48,5 & 3 & 2.500 & 6,65 & 6,1 & 8,4 & 8,4 & 4,0 \\
\hline $10 \mathrm{~A}$ & 17 & 6 & 583 & 8,3 & 24,5 & 1 & 500 & 13,56 & 5,9 & 9,8 & 10,0 & 3,6 \\
\hline $8 \mathrm{~A}$ & 1 & 14 & 1.000 & 5,1 & 11,5 & 0 & 500 & 13,09 & 6,2 & 7,5 & 7,5 & 2,7 \\
\hline $8 \mathrm{~A}$ & 2 & 15 & 1.458 & 6,0 & 12,6 & 2 & 500 & 5,88 & 6,0 & 6,8 & 6,8 & 2,9 \\
\hline $8 \mathrm{~A}$ & 3 & 18 & 1.400 & 6,4 & 14,6 & 3 & 24.750 & 10,71 & 5,8 & 7,5 & 7,5 & 2,9 \\
\hline $8 \mathrm{~A}$ & 4 & 14 & 1.667 & 5,5 & 6,9 & 4 & 5.500 & 6,69 & 5,9 & 7,8 & 7,8 & 3,1 \\
\hline $8 \mathrm{~A}$ & 5 & 14 & 1.333 & 5,1 & 7,3 & 3 & 2.500 & 6,09 & 5,3 & 6,8 & 7,0 & 2,5 \\
\hline $8 \mathrm{~A}$ & 6 & 6 & 1.111 & 6,6 & 13,3 & 3 & 14.500 & 9,11 & 5,9 & 8,5 & 8,5 & 3,3 \\
\hline $8 \mathrm{~A}$ & 7 & 9 & 1.111 & 6,3 & 9,4 & 1 & 47.000 & 6,72 & 6,1 & 9,4 & 9,4 & 3,1 \\
\hline $8 \mathrm{~A}$ & 8 & 13 & 1.417 & 6,8 & 9,9 & 4 & 8.500 & 10,20 & 5,6 & 7,9 & 8,1 & 3,7 \\
\hline $8 \mathrm{~A}$ & 9 & 14 & 1.133 & 5,6 & 7,1 & 6 & 23.500 & 6,61 & 6,1 & 7,6 & 7,6 & 3,0 \\
\hline $8 \mathrm{~A}$ & 10 & 6 & 1.167 & 6,4 & 7,3 & 5 & 25.500 & 13,52 & 5,9 & 7,6 & 7,8 & 2,0 \\
\hline $8 \mathrm{~A}$ & 11 & 12 & 1.133 & 6,5 & 12,4 & 9 & 27.250 & 5,69 & 5,4 & 7,4 & 7,6 & 3,1 \\
\hline $8 \mathrm{~A}$ & 12 & 16 & 1.467 & 7,3 & 15,8 & 8 & 35.750 & 6,33 & 6,1 & 8,3 & 8,3 & 3,1 \\
\hline $8 \mathrm{~A}$ & 13 & 12 & 1.200 & 6,7 & 11,2 & 4 & 18.500 & 8,44 & 5,9 & 7,6 & 7,6 & 3,1 \\
\hline $8 \mathrm{~A}$ & 14 & 15 & 1.333 & 5,8 & 9,1 & 4 & 7.750 & 6,28 & 6,0 & 9,1 & 9,1 & 3,3 \\
\hline $8 \mathrm{~A}$ & 15 & 9 & 933 & 5,5 & 4,5 & 3 & 5.500 & 7,68 & 5,9 & 6,7 & 6,7 & 2,4 \\
\hline
\end{tabular}

$\mathrm{X}_{1}$ : número médio de espécies encontradas, avaliadas no plantio; $\mathrm{X}_{2}$ : número médio de indivíduos avaliados no plantio, por hectare; $\mathrm{X}_{3}$ : altura média das arvores com DAP $>5 \mathrm{~cm} ; X_{4}$ : area basal média dos indivíduos com DAP $>5 \mathrm{~cm} ; X_{5}$ : número médio de espécies regenerantes avaliadas no plantio; $X_{\text {: }}$ número médio de indivíduos regenerantes avaliados por plantio, por hectare; $\mathrm{X}_{7}$ : acúmulo de serapilheira, em $\mathrm{Mg}$ ha ${ }^{-1} ; \mathrm{X}_{8}$ : potencial hidrogeniônico do solo $(\mathrm{pH}) ; \mathrm{X}_{9}$ : soma de bases dos solos $(\mathrm{SB}=\mathrm{Ca}+\mathrm{Mg}+\mathrm{K}+\mathrm{Na})$, em cmolc dm $\mathrm{dm}^{-3} ; \mathrm{X}_{10}$ : capacidade de troca catiônica do solo $(\mathrm{CTC})$, em $\mathrm{cmolc} \mathrm{DM}^{-3} ; \mathrm{X}_{11}: \mathrm{matéria}^{2}$ orgânica do solo, em dag $\mathrm{kg}^{-1}$. 
Tabela 3. Continuação.

\begin{tabular}{|c|c|c|c|c|c|c|c|c|c|c|c|c|}
\hline Área & Parcela & $X_{1}$ & $\mathbf{X}_{2}$ & $\mathbf{X}_{3}$ & $\mathbf{X}_{4}$ & $X_{5}$ & $X_{6}$ & $\mathbf{X}_{7}$ & $\mathbf{X}_{8}$ & $X_{9}$ & $X_{10}$ & $X_{11}$ \\
\hline $8 \mathrm{~A}$ & 16 & 6 & 1.067 & 6,2 & 12,9 & 1 & 250 & 7,18 & 6,2 & 8,1 & 8,1 & 2,9 \\
\hline $8 \mathrm{~A}$ & 17 & 11 & 1.267 & 4,8 & 11,9 & 3 & 33.000 & 8,76 & 6,1 & 7,2 & 7,2 & 2,4 \\
\hline $8 B$ & 1 & 17 & 1.065 & 10,3 & 16,8 & 11 & 11.722 & 6,91 & 6,7 & 13,0 & 13,0 & 4,1 \\
\hline $8 \mathrm{~B}$ & 2 & 20 & 731 & 7,9 & 9,7 & 8 & 1.938 & 8,53 & 6,5 & 11,3 & 11,3 & 3,1 \\
\hline $7 \mathrm{~A}$ & 1 & 4 & 833 & 8,0 & 8,8 & 6 & 5.500 & 8,00 & 6,0 & 6,2 & 6,2 & 3,0 \\
\hline $7 \mathrm{~A}$ & 2 & 8 & 556 & 6,9 & 7,4 & 2 & 10.500 & 16,98 & 6,7 & 7,1 & 7,1 & 3,3 \\
\hline $7 \mathrm{~A}$ & 3 & 7 & 611 & 6,1 & 7,3 & 3 & 2.500 & 9,03 & 6,5 & 6,3 & 6,3 & 3,3 \\
\hline $7 \mathrm{~A}$ & 4 & 7 & 944 & 7,1 & 7,3 & 5 & 20.000 & 6,95 & 5,6 & 3,5 & 3,7 & 2,6 \\
\hline $7 \mathrm{~A}$ & 5 & 10 & 1.333 & 7,0 & 7,9 & 6 & 19.000 & 4,26 & 5,4 & 2,2 & 2,6 & 2,2 \\
\hline $7 \mathrm{~A}$ & 6 & 3 & 667 & 9,3 & 15,2 & 1 & 5.500 & 15,59 & 5,4 & 4,9 & 5,1 & 3,0 \\
\hline $6 \mathrm{~A}$ & 1 & 15 & 1.111 & 4,7 & 16,7 & 0 & 0 & 8,94 & 6,5 & 13,1 & 13,1 & 3,6 \\
\hline $6 \mathrm{~A}$ & 2 & 10 & 1.200 & 4,4 & 7,6 & 0 & 0 & 8,26 & 6,7 & 15,6 & 15,6 & 3,4 \\
\hline $6 \mathrm{~A}$ & 3 & 8 & 611 & 3,6 & 3,6 & 0 & 0 & 3,92 & 6,6 & 8,6 & 8,6 & 3,3 \\
\hline $5 \mathrm{~A}$ & 1 & 9 & 708 & 2,8 & 1,6 & 1 & 4.000 & 3,02 & 5,9 & 10,3 & 10,3 & 3,3 \\
\hline $5 \mathrm{~A}$ & 2 & 18 & 1.625 & 4,2 & 8,4 & 3 & 2.000 & 6,44 & 5,9 & 6,7 & 6,7 & 2,6 \\
\hline $5 \mathrm{~A}$ & 3 & 16 & 1.458 & 3,5 & 5,6 & 0 & 500 & 2,12 & 6,1 & 6,6 & 6,6 & 2,1 \\
\hline $4 \mathrm{~A}$ & 1 & 18 & 1.524 & 3,5 & 3,9 & 0 & 500 & 7,34 & 6,5 & 8,7 & 8,7 & 3,7 \\
\hline $4 \mathrm{~A}$ & 2 & 16 & 2.000 & 3,6 & 3,1 & 2 & 2.000 & 4,01 & 6,6 & 6,7 & 6,7 & 3,4 \\
\hline $4 \mathrm{~A}$ & 3 & 14 & 1.583 & 4,6 & 12,5 & 0 & 500 & 3,89 & 6,5 & 13,6 & 13,6 & 3,7 \\
\hline $3 \mathrm{~A}$ & 1 & 29 & 1.479 & 1,9 & 0,3 & 0 & 0 & 0,0 & 6,1 & 3,8 & 3,8 & 2,5 \\
\hline $3 \mathrm{~A}$ & 2 & 22 & 1.222 & 2,1 & 0,2 & 0 & 0 & 0,0 & 6,0 & 3,2 & 3,2 & 2,2 \\
\hline $3 \mathrm{~A}$ & 3 & 15 & 1.455 & 1,8 & 0,3 & 0 & 0 & 0,0 & 5,8 & 2,4 & 2,4 & 2,4 \\
\hline $3 \mathrm{~A}$ & 4 & 17 & 1.429 & 2,4 & 0,2 & 0 & 0 & 0,0 & 5,8 & 3,2 & 3,2 & 2,5 \\
\hline $3 \mathrm{~A}$ & 5 & 24 & 1.357 & 2,7 & 0,7 & 0 & 0 & 0,0 & 6,2 & 4,1 & 4,1 & 2,6 \\
\hline $2 \mathrm{~A}$ & 1 & 10 & 1.222 & 1,8 & 1,2 & 0 & 0 & 0,0 & 6,6 & 13,6 & 13,6 & 3,4 \\
\hline $2 \mathrm{~A}$ & 2 & 8 & 1.278 & 1,8 & 0,9 & 0 & 0 & 0,0 & 6,1 & 14,8 & 14,8 & 4,1 \\
\hline $2 \mathrm{~A}$ & 3 & 12 & 1.533 & 1,2 & 0,1 & 0 & 0 & 0,0 & 6,4 & 13,8 & 13,8 & 3,7 \\
\hline $2 \mathrm{~A}$ & 4 & 12 & 1.278 & 1,8 & 0,7 & 0 & 0 & 0,0 & 6,4 & 13,9 & 13,9 & 3,8 \\
\hline $2 \mathrm{~A}$ & 5 & 15 & 1.889 & 1,8 & 0,7 & 0 & 0 & 0,0 & 6,5 & 14,7 & 14,7 & 3,7 \\
\hline $2 \mathrm{~A}$ & 6 & 7 & 1.333 & 3,2 & 1,6 & 0 & 0 & 0,0 & 6,5 & 13,2 & 13,2 & 3,4 \\
\hline $1 \mathrm{~A}$ & 1 & 7 & 1.524 & 0,4 & 0,0 & 0 & 0 & 0,0 & 6,5 & 6,9 & 6,9 & 2,9 \\
\hline $1 \mathrm{~A}$ & 2 & 8 & 1.667 & 0,6 & 0,0 & 0 & 0 & 0,0 & 6,2 & 8,0 & 8,0 & 3,1 \\
\hline $1 \mathrm{~A}$ & 3 & 7 & 1.222 & 0,6 & 0,0 & 0 & 0 & 0,0 & 6,9 & 16,4 & 16,4 & 4,1 \\
\hline
\end{tabular}

$\mathrm{X}_{1}$ : número médio de espécies encontradas, avaliadas no plantio; $\mathrm{X}_{2}$ : número médio de indivíduos avaliados no plantio, por hectare; $\mathrm{X}_{3}$ : altura média das arvores com DAP $>5 \mathrm{~cm} ; X_{4}$ : area basal média dos indivíduos com DAP $>5 \mathrm{~cm} ; X_{5}$ : número médio de espécies regenerantes avaliadas no plantio; $X_{6}$ : número médio de indivíduos regenerantes avaliados por plantio, por hectare; $\mathrm{X}_{7}$ : acúmulo de serapilheira, em $\mathrm{Mg}$ ha ${ }^{-1} ; \mathrm{X}_{8}$ : potencial hidrogeniônico do solo

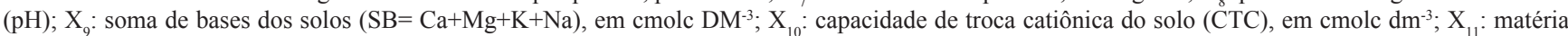
orgânica do solo, em dag $\mathrm{kg}^{-1}$. 
Tabela 4. Notas atribuídas às variáveis, somatório das variáveis (escore), pré-classificação da parcela (C1) e classificação final pela função discriminante (C) em parcelas não restauradas (1) ou parcelas parcialmente restauradas (2).

\begin{tabular}{|c|c|c|c|c|c|c|c|c|c|c|c|c|c|c|c|}
\hline Área & Parcela & $X_{1}$ & $X_{2}$ & $\mathbf{X}_{3}$ & $X_{4}$ & $X_{5}$ & $X_{6}$ & $\mathbf{X}_{7}$ & $\mathbf{X}_{8}$ & $X_{9}$ & $X_{10}$ & $X_{11}$ & Escore & $\mathrm{C1}$ & C \\
\hline $15 \mathrm{~A}$ & 1 & 5,93 & 9,83 & 8,08 & 14,02 & 1,60 & 0,61 & 10,65 & 9,39 & 8,33 & 8,24 & 8,23 & 159,74 & 1 & 1 \\
\hline $15 \mathrm{~A}$ & 2 & 6,67 & 8,98 & 8,82 & 5,15 & 2,40 & 1,42 & 12,13 & 9,91 & 9,41 & 9,31 & 5,58 & 142,81 & 1 & 1 \\
\hline $15 \mathrm{~A}$ & 3 & 5,19 & 6,41 & 11,75 & 8,50 & 2,40 & 1,62 & 18,40 & 9,91 & 11,27 & 11,15 & 10,09 & 172,51 & 2 & 0 \\
\hline $15 \mathrm{~A}$ & 4 & 7,41 & 10,69 & 10,75 & 10,96 & 3,20 & 3,65 & 8,12 & 9,57 & 9,41 & 9,31 & 7,70 & 167,69 & 2 & 2 \\
\hline $14 \mathrm{~A}$ & 1 & 4,44 & 9,24 & 14,40 & 22,10 & 1,60 & 1,42 & 11,25 & 9,74 & 10,65 & 10,53 & 10,62 & 200,94 & 2 & 2 \\
\hline $14 \mathrm{~A}$ & 2 & 9,63 & 10,63 & 10,88 & 14,39 & 4,00 & 3,52 & 6,82 & 9,91 & 7,25 & 7,18 & 8,23 & 174,26 & 2 & 2 \\
\hline $14 \mathrm{~A}$ & 3 & 8,89 & 8,78 & 9,82 & 18,25 & 2,40 & 3,85 & 6,28 & 10,26 & 10,96 & 10,84 & 11,68 & 192,936 & 2 & 2 \\
\hline $14 \mathrm{~A}$ & 4 & 10,37 & 9,71 & 10,72 & 20,02 & 2,40 & 2,03 & 10,35 & 10,96 & 12,04 & 11,91 & 9,82 & 211,56 & 2 & 2 \\
\hline $14 \mathrm{~A}$ & 5 & 6,67 & 6,93 & 15,32 & 18,07 & 3,20 & 1,42 & 10,07 & 10,78 & 16,82 & 16,64 & 13,01 & 220,016 & 2 & 2 \\
\hline $14 \mathrm{~A}$ & 6 & 8,15 & 10,17 & 9,99 & 14,87 & 4,80 & 3,25 & 5,68 & 10,43 & 11,88 & 11,76 & 12,21 & 193,39 & 2 & 2 \\
\hline $14 \mathrm{~A}$ & 7 & 8,89 & 9,71 & 8,23 & 13,12 & 2,40 & 1,62 & 8,21 & 10,96 & 15,90 & 15,73 & 12,74 & 198,61 & 2 & 2 \\
\hline $14 \mathrm{~A}$ & 8 & 8,15 & 13,40 & 10,21 & 23,32 & 1,60 & 1,22 & 11,47 & 10,43 & 15,90 & 15,73 & 11,68 & 238,80 & 2 & 2 \\
\hline $14 \mathrm{~B}$ & 1 & 8,89 & 10,33 & 8,44 & 8,83 & 8,80 & 8,72 & 12,26 & 10,26 & 11,88 & 11,76 & 11,42 & 210,69 & 2 & 2 \\
\hline 14B & 2 & 7,41 & 6,48 & 10,97 & 11,71 & 11,20 & 11,52 & 5,15 & 9,91 & 10,49 & 10,38 & 10,09 & 202,57 & 2 & 2 \\
\hline $14 \mathrm{~B}$ & 3 & 9,63 & 7,13 & 7,71 & 6,43 & 12,00 & 10,95 & 8,76 & 10,26 & 9,10 & 9,01 & 6,90 & 189,32 & 2 & 2 \\
\hline $14 B$ & 4 & 10,37 & 8,55 & 10,54 & 11,05 & 8,80 & 9,74 & 14,55 & 10,26 & 10,80 & 10,69 & 11,42 & 221,17 & 2 & 2 \\
\hline 14B & 5 & 14,81 & 13,62 & 12,14 & 14,14 & 7,20 & 8,11 & 10,54 & 9,91 & 9,10 & 9,31 & 10,09 & 227,16 & 2 & 2 \\
\hline $14 \mathrm{~B}$ & 6 & 8,89 & 13,90 & 10,20 & 7,84 & 12,00 & 10,95 & 8,74 & 9,39 & 8,64 & 8,85 & 10,09 & 209,15 & 2 & 2 \\
\hline $13 \mathrm{~A}$ & 1 & 15,56 & 9,80 & 10,43 & 6,60 & 6,40 & 3,35 & 9,54 & 10,26 & 9,26 & 9,16 & 8,76 & 210,01 & 2 & 2 \\
\hline $13 \mathrm{~A}$ & 2 & 11,85 & 6,42 & 12,49 & 6,64 & 10,40 & 4,62 & 7,28 & 10,26 & 9,26 & 9,16 & 7,96 & 43,67 & 2 & 2 \\
\hline $13 \mathrm{~A}$ & 3 & 14,81 & 7,72 & 10,43 & 5,52 & 8,80 & 2,89 & 8,99 & 10,43 & 11,42 & 11,30 & 7,70 & 181,79 & 2 & 2 \\
\hline $13 \mathrm{~A}$ & 4 & 17,04 & 8,67 & 10,67 & 5,88 & 12,00 & 6,14 & 7,35 & 10,61 & 11,57 & 11,45 & 7,96 & 179,00 & 2 & 2 \\
\hline $13 \mathrm{~A}$ & 5 & 12,59 & 6,59 & 12,34 & 5,76 & 10,40 & 3,74 & 7,55 & 10,61 & 16,05 & 15,88 & 9,03 & 185,79 & 2 & 2 \\
\hline $12 \mathrm{~A}$ & 1 & 3,70 & 4,96 & 15,45 & 26,84 & 3,20 & 1,83 & 7,66 & 10,78 & 11,88 & 11,76 & 10,62 & 207,33 & 2 & 2 \\
\hline $12 \mathrm{~A}$ & 2 & 5,93 & 5,78 & 10,83 & 13,96 & 4,80 & 5,27 & 4,65 & 10,09 & 12,35 & 12,21 & 13,01 & 205,25 & 2 & 2 \\
\hline $12 \mathrm{~A}$ & 3 & 8,15 & 6,61 & 10,84 & 10,51 & 2,40 & 2,03 & 14,91 & 10,43 & 14,97 & 14,81 & 14,07 & 210,54 & 2 & 2 \\
\hline $12 \mathrm{~A}$ & 4 & 5,93 & 7,85 & 13,32 & 16,16 & 4,00 & 4,87 & 9,55 & 10,43 & 11,27 & 11,15 & 13,01 & 182,60 & 2 & 2 \\
\hline $12 \mathrm{~A}$ & 5 & 6,67 & 9,09 & 10,42 & 7,09 & 1,60 & 0,61 & 6,76 & 10,09 & 11,27 & 11,15 & 12,74 & 197,01 & 1 & 1 \\
\hline $12 \mathrm{~A}$ & 6 & 9,63 & 10,74 & 9,76 & 19,67 & 4,00 & 1,49 & 4,45 & 10,09 & 10,34 & 10,23 & 10,62 & 198,45 & 2 & 2 \\
\hline $12 \mathrm{~A}$ & 7 & 8,89 & 13,22 & 10,16 & 16,46 & 4,00 & 3,04 & 6,13 & 10,43 & 10,03 & 9,92 & 10,88 & 150,41 & 2 & 2 \\
\hline $12 \mathrm{~A}$ & 8 & 8,15 & 9,09 & 11,96 & 12,18 & 3,20 & 2,30 & 9,48 & 9,57 & 9,57 & 9,47 & 11,68 & 195,23 & 2 & 2 \\
\hline $12 \mathrm{~A}$ & 9 & 2,96 & 2,48 & 9,81 & 3,61 & 1,60 & 2,43 & 9,38 & 10,96 & 13,27 & 13,13 & 11,68 & 195,33 & 1 & 1 \\
\hline $12 \mathrm{~A}$ & 10 & 5,93 & 4,54 & 13,09 & 9,74 & 1,60 & 0,27 & 6,19 & 9,39 & 5,56 & 6,26 & 10,88 & 175,43 & 1 & 1 \\
\hline $12 \mathrm{~A}$ & 11 & 2,96 & 2,48 & 13,36 & 8,41 & 1,60 & 1,01 & 6,25 & 8,87 & 5,86 & 6,56 & 10,88 & 135,39 & 1 & 1 \\
\hline $10 \mathrm{~A}$ & 1 & 7,41 & 5,70 & 8,20 & 4,31 & 8,80 & 4,19 & 7,36 & 9,57 & 10,19 & 10,38 & 7,17 & 124,89 & 1 & 1 \\
\hline $10 \mathrm{~A}$ & 2 & 8,15 & 7,13 & 7,96 & 3,36 & 5,60 & 2,64 & 5,46 & 9,74 & 14,51 & 14,35 & 7,70 & 113,41 & 1 & 1 \\
\hline $10 \mathrm{~A}$ & 3 & 8,15 & 8,14 & 8,27 & 4,26 & 4,00 & 1,22 & 7,35 & 9,91 & 19,14 & 18,93 & 9,56 & 154,71 & 2 & 2 \\
\hline $10 \mathrm{~A}$ & 4 & 10,37 & 10,18 & 7,33 & 5,64 & 8,00 & 4,87 & 7,38 & 9,57 & 16,05 & 15,88 & 10,88 & 156,74 & 2 & 2 \\
\hline $10 \mathrm{~A}$ & 5 & 8,89 & 8,91 & 8,73 & 6,85 & 3,20 & 2,43 & 15,44 & 9,57 & 10,96 & 10,84 & 9,03 & 178,37 & 2 & 2 \\
\hline
\end{tabular}

$\mathrm{X}_{1}$ : número médio de espécies encontradas, avaliadas no plantio; $\mathrm{X}_{2}$ : número médio de indivíduos avaliados no plantio; $\mathrm{X}_{3}$ : altura média das arvores com DAP $>5 \mathrm{~cm} ; X_{4}$ : area basal média dos indivíduos com DAP $>5 \mathrm{~cm} ; X_{5}$ : número médio de espécies regenerantes avaliadas no plantio; $X_{6}$ : número médio de indivíduos regenerantes avaliados por plantio; $\mathrm{X}_{7}$ : acúmulo de serapilheira; $\mathrm{X}_{\mathrm{s}}$ : potencial hidrogeniônico do solo $(\mathrm{pH})$; $\mathrm{X}_{0}$ : soma de bases dos solos $(\mathrm{SB}=$ $\mathrm{Ca}+\mathrm{Mg}+\mathrm{K}+\mathrm{Na}) ; \mathrm{X}_{10}$ : capacidade de troca catiônica do solo (CTC); $\mathrm{X}_{11}$ : matéria orgânica do solo. 
Tabela 4. Continuação.

\begin{tabular}{|c|c|c|c|c|c|c|c|c|c|c|c|c|c|c|c|}
\hline Área & Parcela & $X_{1}$ & $\mathbf{X}_{2}$ & $\mathbf{X}_{3}$ & $\mathbf{X}_{4}$ & $X_{5}$ & $X_{6}$ & $\mathbf{X}_{7}$ & $\mathbf{X}_{8}$ & $X_{9}$ & $X_{10}$ & $X_{11}$ & Escore & $\mathrm{C} 1$ & $\mathrm{C}$ \\
\hline $10 \mathrm{~A}$ & 6 & 6,67 & 8,55 & 8,96 & 7,19 & 7,20 & 6,09 & 5,45 & 9,91 & 10,49 & 10,38 & 8,23 & 198,15 & 1 & 1 \\
\hline $10 \mathrm{~A}$ & 7 & 7,41 & 9,69 & 8,94 & 5,88 & 3,20 & 1,22 & 7,50 & 9,74 & 12,96 & 12,82 & 9,56 & 172,41 & 1 & 1 \\
\hline $10 \mathrm{~A}$ & 8 & 5,93 & 5,70 & 9,11 & 3,82 & 2,40 & 1,01 & 8,40 & 9,39 & 7,25 & 7,63 & 7,17 & 165,53 & 1 & 1 \\
\hline $10 \mathrm{~A}$ & 9 & 6,67 & 8,55 & 10,44 & 11,76 & 3,20 & 1,42 & 15,54 & 9,91 & 11,27 & 11,15 & 8,23 & 158,69 & 2 & 2 \\
\hline $10 \mathrm{~A}$ & 10 & 5,19 & 5,70 & 9,83 & 5,07 & 4,00 & 8,92 & 14,68 & 9,74 & 11,27 & 11,45 & 9,03 & 116,18 & 2 & 2 \\
\hline $10 \mathrm{~A}$ & 11 & 10,37 & 8,55 & 9,37 & 11,88 & 4,00 & 7,91 & 9,73 & 9,74 & 10,80 & 10,99 & 7,96 & 182,63 & 2 & 2 \\
\hline $10 \mathrm{~A}$ & 12 & 8,89 & 7,74 & 9,97 & 6,87 & 2,40 & 4,67 & 7,92 & 9,74 & 11,73 & 11,60 & 12,21 & 170,22 & 1 & 2 \\
\hline $10 \mathrm{~A}$ & 13 & 6,67 & 6,27 & 11,39 & 7,16 & 3,20 & 10,95 & 9,53 & 10,09 & 14,35 & 14,20 & 8,23 & 191,43 & 2 & 2 \\
\hline $10 \mathrm{~A}$ & 14 & 3,70 & 9,98 & 15,03 & 20,28 & 0,80 & 1,22 & 16,65 & 9,74 & 11,27 & 11,45 & 10,09 & 164,81 & 2 & 2 \\
\hline $10 \mathrm{~A}$ & 15 & 2,22 & 5,70 & 16,60 & 18,58 & 2,40 & 1,22 & 10,94 & 9,04 & 11,57 & 11,91 & 12,21 & 184,73 & 2 & 2 \\
\hline $10 \mathrm{~A}$ & 16 & 2,96 & 8,55 & 18,37 & 20,15 & 2,40 & 2,03 & 6,09 & 10,61 & 12,96 & 12,82 & 10,62 & 206,62 & 2 & 2 \\
\hline $10 \mathrm{~A}$ & 17 & 4,44 & 4,99 & 10,44 & 10,19 & 0,80 & 0,41 & 12,42 & 10,26 & 15,12 & 15,27 & 9,56 & 187,91 & 2 & 2 \\
\hline $8 \mathrm{~A}$ & 1 & 10,37 & 8,55 & 6,44 & 4,77 & 0,00 & 0,41 & 11,99 & 10,78 & 11,57 & 11,45 & 7,17 & 237,73 & 1 & 1 \\
\hline $8 \mathrm{~A}$ & 2 & 11,11 & 12,47 & 7,51 & 5,25 & 1,60 & 0,41 & 5,39 & 10,43 & 10,49 & 10,38 & 7,70 & 191,04 & 1 & 1 \\
\hline $8 \mathrm{~A}$ & 3 & 13,33 & 11,97 & 7,99 & 6,08 & 2,40 & 20,08 & 9,81 & 10,09 & 11,57 & 11,45 & 7,70 & 147,39 & 2 & 2 \\
\hline $8 \mathrm{~A}$ & 4 & 10,37 & 14,25 & 6,85 & 2,88 & 3,20 & 4,46 & 6,13 & 10,26 & 12,04 & 11,91 & 8,23 & 146,68 & 1 & 1 \\
\hline $8 \mathrm{~A}$ & 5 & 10,37 & 11,40 & 6,36 & 3,02 & 2,40 & 2,03 & 5,58 & 9,22 & 10,49 & 10,69 & 6,64 & 207,64 & 1 & 1 \\
\hline $8 \mathrm{~A}$ & 6 & 4,44 & 9,50 & 8,20 & 5,53 & 2,40 & 11,76 & 8,35 & 10,26 & 13,12 & 12,98 & 8,76 & 161,91 & 2 & 2 \\
\hline $8 \mathrm{~A}$ & 7 & 6,67 & 9,50 & 7,89 & 3,92 & 0,80 & 38,13 & 6,16 & 10,61 & 14,51 & 14,35 & 8,23 & 139,61 & 2 & 2 \\
\hline $8 \mathrm{~A}$ & 8 & 9,63 & 12,11 & 8,51 & 4,10 & 3,20 & 6,90 & 9,34 & 9,74 & 12,19 & 12,37 & 9,82 & 171,33 & 2 & 2 \\
\hline $8 \mathrm{~A}$ & 9 & 10,37 & 9,69 & 7,00 & 2,94 & 4,80 & 19,07 & 6,06 & 10,61 & 11,73 & 11,60 & 7,96 & 219,54 & 2 & 2 \\
\hline $8 \mathrm{~A}$ & 10 & 4,44 & 9,98 & 7,96 & 3,05 & 4,00 & 20,69 & 12,39 & 10,26 & 11,73 & 11,91 & 5,31 & 175,06 & 2 & 2 \\
\hline $8 \mathrm{~A}$ & 11 & 8,89 & 9,69 & 8,10 & 5,15 & 7,20 & 22,11 & 5,21 & 9,39 & 11,42 & 11,60 & 8,23 & 185,83 & 2 & 2 \\
\hline $8 \mathrm{~A}$ & 12 & 11,85 & 12,54 & 9,11 & 6,57 & 6,40 & 29,01 & 5,80 & 10,61 & 12,81 & 12,67 & 8,23 & 186,95 & 2 & 2 \\
\hline $8 \mathrm{~A}$ & 13 & 8,89 & 10,26 & 8,42 & 4,63 & 3,20 & 15,01 & 7,73 & 10,26 & 11,73 & 11,60 & 8,23 & 200,62 & 2 & 2 \\
\hline $8 \mathrm{~A}$ & 14 & 11,11 & 11,40 & 7,30 & 3,78 & 3,20 & 6,29 & 5,76 & 10,43 & 14,04 & 13,89 & 8,76 & 236,20 & 2 & 2 \\
\hline $8 \mathrm{~A}$ & 15 & 6,67 & 7,98 & 6,89 & 1,85 & 2,40 & 4,46 & 7,03 & 10,26 & 10,34 & 10,23 & 6,37 & 180,85 & 1 & 1 \\
\hline $8 \mathrm{~A}$ & 16 & 4,44 & 9,12 & 7,72 & 5,36 & 0,80 & 0,20 & 6,57 & 10,78 & 12,50 & 12,37 & 7,70 & 172,42 & 1 & 1 \\
\hline $8 \mathrm{~A}$ & 17 & 8,15 & 10,83 & 5,99 & 4,95 & 2,40 & 26,77 & 8,02 & 10,61 & 11,11 & 10,99 & 6,37 & 129,70 & 2 & 2 \\
\hline $8 \mathrm{~B}$ & 1 & 12,59 & 9,10 & 12,90 & 7,00 & 8,80 & 9,51 & 6,33 & 11,65 & 20,06 & 19,85 & 10,88 & 198,10 & 2 & 2 \\
\hline $8 B$ & 2 & 14,81 & 6,25 & 9,90 & 4,04 & 6,40 & 1,57 & 7,82 & 11,30 & 17,44 & 17,25 & 8,23 & 168,54 & 2 & 2 \\
\hline $7 \mathrm{~A}$ & 1 & 2,96 & 7,13 & 10,02 & 3,66 & 4,80 & 4,46 & 7,33 & 10,43 & 9,57 & 9,47 & 7,96 & 135,09 & 1 & 1 \\
\hline $7 \mathrm{~A}$ & 2 & 5,93 & 4,75 & 8,64 & 3,08 & 1,60 & 8,52 & 15,55 & 11,65 & 10,96 & 10,84 & 8,76 & 196,79 & 1 & 1 \\
\hline $7 \mathrm{~A}$ & 3 & 5,19 & 5,23 & 7,69 & 3,02 & 2,40 & 2,03 & 8,27 & 11,30 & 9,72 & 9,62 & 8,76 & 135,63 & 1 & 1 \\
\hline $7 \mathrm{~A}$ & 4 & 5,19 & 8,08 & 8,84 & 3,03 & 4,00 & 16,23 & 6,37 & 9,74 & 5,40 & 5,65 & 6,90 & 156,19 & 1 & 1 \\
\hline $7 \mathrm{~A}$ & 5 & 7,41 & 11,40 & 8,71 & 3,30 & 4,80 & 15,42 & 3,91 & 9,39 & 3,40 & 3,97 & 5,84 & 124,11 & 1 & 1 \\
\hline $7 \mathrm{~A}$ & 6 & 2,22 & 5,70 & 11,59 & 6,33 & 0,80 & 4,46 & 14,28 & 9,39 & 7,56 & 7,79 & 7,96 & 140,40 & 1 & 1 \\
\hline $6 \mathrm{~A}$ & 1 & 11,11 & 9,50 & 5,89 & 6,92 & 0,00 & 0,00 & 8,19 & 11,30 & 20,22 & 20,00 & 9,56 & 139,23 & 2 & 2 \\
\hline $6 \mathrm{~A}$ & 2 & 7,41 & 10,26 & 5,50 & 3,17 & 0,00 & 0,00 & 7,57 & 11,65 & 24,07 & 23,82 & 9,03 & 134,35 & 2 & 2 \\
\hline
\end{tabular}

$\mathrm{X}_{1}$ : número médio de espécies encontradas, avaliadas no plantio; $\mathrm{X}_{2}$ : número médio de indivíduos avaliados no plantio; $\mathrm{X}_{3}$ : altura média das arvores com DAP $>5 \mathrm{~cm} ; X_{4}$ : area basal média dos indivíduos com DAP $>5 \mathrm{~cm} ; X_{s}$ : número médio de espécies regenerantes avaliadas no plantio; $X_{6}$ : número médio de indivíduos regenerantes avaliados por plantio; $\mathrm{X}_{7}$ : acúmulo de serapilheira; $\mathrm{X}_{8}$ : potencial hidrogeniônico do solo $(\mathrm{pH})$; $\mathrm{X}_{9}$ : soma de bases dos solos $(\mathrm{SB}=$ $\mathrm{Ca}+\mathrm{Mg}+\mathrm{K}+\mathrm{Na}) ; \mathrm{X}_{10}$ : capacidade de troca catiônica do solo (CTC); $\mathrm{X}_{11}$ : matéria orgânica do solo. 
Tabela 4. Continuação.

\begin{tabular}{|c|c|c|c|c|c|c|c|c|c|c|c|c|c|c|c|}
\hline Área & Parcela & $\mathbf{X}_{1}$ & $\mathbf{X}_{2}$ & $X_{3}$ & $\mathbf{X}_{4}$ & $X_{5}$ & $X_{6}$ & $\mathbf{X}_{7}$ & $X_{8}$ & $X_{9}$ & $X_{10}$ & $X_{11}$ & Escore & $\mathrm{C} 1$ & C \\
\hline $6 \mathrm{~A}$ & 3 & 5,93 & 5,23 & 4,48 & 1,50 & 0,00 & 0,00 & 3,60 & 11,48 & 13,27 & 13,13 & 8,76 & 185,56 & 1 & 1 \\
\hline $5 \mathrm{~A}$ & 1 & 6,67 & 6,06 & 3,55 & 0,66 & 0,80 & 3,25 & 2,77 & 10,26 & 15,90 & 15,73 & 8,76 & 181,94 & 1 & 1 \\
\hline $5 \mathrm{~A}$ & 2 & 13,33 & 13,90 & 5,22 & 3,47 & 2,40 & 1,62 & 5,90 & 10,26 & 10,34 & 10,23 & 6,90 & 111,52 & 1 & 1 \\
\hline $5 \mathrm{~A}$ & 3 & 11,85 & 12,47 & 4,39 & 2,33 & 0,00 & 0,41 & 1,95 & 10,61 & 10,19 & 10,08 & 5,58 & 127,65 & 1 & 1 \\
\hline $4 \mathrm{~A}$ & 1 & 13,33 & 13,03 & 4,41 & 1,62 & 0,00 & 0,41 & 6,72 & 11,30 & 13,43 & 13,28 & 9,82 & 150,64 & 1 & 1 \\
\hline $4 \mathrm{~A}$ & 2 & 11,85 & 17,10 & 4,51 & 1,28 & 1,60 & 1,62 & 3,68 & 11,48 & 10,34 & 10,23 & 9,03 & 121,44 & 1 & 1 \\
\hline $4 \mathrm{~A}$ & 3 & 10,37 & 13,54 & 5,76 & 5,18 & 0,00 & 0,41 & 3,56 & 11,30 & 20,99 & 20,76 & 9,82 & 150,80 & 2 & 2 \\
\hline $3 \mathrm{~A}$ & 1 & 21,48 & 12,65 & 2,36 & 0,10 & 0,00 & 0,00 & 0,00 & 10,61 & 5,86 & 5,80 & 6,64 & & 1 & 1 \\
\hline $3 \mathrm{~A}$ & 2 & 16,30 & 10,45 & 2,58 & 0,07 & 0,00 & 0,00 & 0,00 & 10,43 & 4,94 & 4,89 & 5,84 & 181,69 & 1 & 1 \\
\hline $3 \mathrm{~A}$ & 3 & 11,11 & 12,44 & 2,23 & 0,11 & 0,00 & 0,00 & 0,00 & 10,09 & 3,70 & 3,66 & 6,37 & 111,51 & 1 & 1 \\
\hline $3 \mathrm{~A}$ & 4 & 12,59 & 12,22 & 3,04 & 0,08 & 0,00 & 0,00 & 0,00 & 10,09 & 4,94 & 4,89 & 6,64 & 92,22 & 1 & 1 \\
\hline $3 \mathrm{~A}$ & 5 & 17,78 & 11,60 & 3,32 & 0,28 & 0,00 & 0,00 & 0,00 & 10,78 & 6,33 & 6,26 & 6,90 & 80,86 & 1 & 1 \\
\hline $2 \mathrm{~A}$ & 1 & 7,41 & 10,45 & 2,23 & 0,48 & 0,00 & 0,00 & 0,00 & 11,48 & 20,99 & 20,76 & 9,03 & 89,27 & 1 & 1 \\
\hline $2 \mathrm{~A}$ & 2 & 5,93 & 10,93 & 2,20 & 0,35 & 0,00 & 0,00 & 0,00 & 10,61 & 22,84 & 22,60 & 10,88 & 105,78 & 1 & 1 \\
\hline $2 \mathrm{~A}$ & 3 & 8,89 & 13,11 & 1,49 & 0,05 & 0,00 & 0,00 & 0,00 & 11,13 & 21,30 & 21,07 & 9,82 & 143,40 & 1 & 1 \\
\hline $2 \mathrm{~A}$ & 4 & 8,89 & 10,93 & 2,24 & 0,30 & 0,00 & 0,00 & 0,00 & 11,13 & 21,45 & 21,22 & 10,09 & 149,33 & 1 & 1 \\
\hline $2 \mathrm{~A}$ & 5 & 11,11 & 16,15 & 2,23 & 0,28 & 0,00 & 0,00 & 0,00 & 11,30 & 22,69 & 22,44 & 9,82 & 151,32 & 2 & 1 \\
\hline $2 \mathrm{~A}$ & 6 & 5,19 & 11,40 & 4,00 & 0,65 & 0,00 & 0,00 & 0,00 & 11,30 & 20,37 & 20,15 & 9,03 & 149,33 & 1 & 1 \\
\hline $1 \mathrm{~A}$ & 1 & 5,19 & 13,03 & 0,49 & 0,00 & 0,00 & 0,00 & 0,00 & 11,30 & 10,65 & 10,53 & 7,70 & 168,97 & 1 & 1 \\
\hline $1 \mathrm{~A}$ & 2 & 5,93 & 14,25 & 0,73 & 0,00 & 0,00 & 0,00 & 0,00 & 10,78 & 12,35 & 12,21 & 8,23 & 140,49 & 1 & 1 \\
\hline $1 \mathrm{~A}$ & 3 & 5,19 & 10,45 & 0,80 & 0,00 & 0,00 & 0,00 & 0,00 & 12,00 & 25,31 & 25,04 & 10,88 & 98,29 & 1 & 1 \\
\hline
\end{tabular}

$\mathrm{X}_{1}$ : número médio de espécies encontradas, avaliadas no plantio; $\mathrm{X}_{2}$ : número médio de indivíduos avaliados no plantio; $\mathrm{X}_{3}$ : altura média das arvores com DAP $>5 \mathrm{~cm} ; \mathrm{X}_{4}$ : area basal média dos indivíduos com DAP $>5 \mathrm{~cm} ; \mathrm{X}_{5}$ : número médio de espécies regenerantes avaliadas no plantio; $\mathrm{X}_{6}$ : número médio de indivíduos regenerantes avaliados por plantio; $\mathrm{X}_{7}$ : acúmulo de serapilheira; $\mathrm{X}_{8}$ : potencial hidrogeniônico do solo $(\mathrm{pH})$; $\mathrm{X}_{9}$ : soma de bases dos solos $(\mathrm{SB}=$ $\mathrm{Ca}+\mathrm{Mg}+\mathrm{K}+\mathrm{Na}) ; \mathrm{X}_{10}$ : capacidade de troca catiônica do solo (CTC); $\mathrm{X}_{11}$ : matéria orgânica do solo.

Partindo-se das onze variáveis iniciais, seis foram selecionadas pela análise (backward) para a criação da função discriminante final: número de espécies plantadas $\left(\mathrm{X}_{1}\right)$, área basal dos indivíduos plantados $\left(\mathrm{m}^{2} \cdot \mathrm{ha}^{-1}\right)\left(\mathrm{X}_{4}\right)$, número de espécies regenerantes $\left(\mathrm{X}_{5}\right)$, número de indivíduos regenerantes (ind.ha $\left.{ }^{-1}\right)\left(\mathrm{X}_{6}\right)$, acúmulo de serapilheira $\left(\mathrm{Mg} \cdot \mathrm{ha}^{-1}\right)\left(\mathrm{X}_{7}\right)$ e capacidade de troca catiônica (CTC) do solo $\left(\mathrm{cmolc}^{-\mathrm{dm}^{-3}}\right)\left(\mathrm{X}_{10}\right)$. As outras cinco variáveis apresentaram pouca ou nenhuma variação no erro de classificação com a sua eliminação na função discriminante e, devido a isso, foram excluídas da função discriminante gerada. Os coeficientes que originaram a função discriminante são apresentados na Tabela 5.

A análise discriminante permitiu, além da classificação de elementos amostrais, a predição do erro de classificação. No presente trabalho, o erro de classificação foi de $2,05 \%$, e a categorização das parcelas nos grupos parcialmente restauradas ou não restauradas utilizando as seis variáveis selecionadas pela função discriminante coincidiu com a categorização inicial, utilizando-se as onze variáveis, em $98 \%$ das parcelas.

Tabela 5. Coeficientes gerados pela função discriminante.

\begin{tabular}{ccc}
\hline Variável & C1 & C2 \\
\hline Constante & $-20,52314$ & $-41,93040$ \\
$\mathrm{X}_{1}$ & 1,24551 & 1,65560 \\
$\mathrm{X}_{4}$ & 0,37415 & 0,62270 \\
$\mathrm{X}_{5}$ & 0,17833 & 0,45852 \\
$\mathrm{X}_{6}$ & 0,0004153 & 0,0006812 \\
$\mathrm{X}_{7}$ & 0,0009225 & 0,00126 \\
$\mathrm{X}_{10}$ & 2,36860 & 3,30331 \\
\hline
\end{tabular}


Do total de 99 parcelas avaliadas nos reflorestamentos, apenas duas foram classificadas incorretamente.

A função discriminante linear de Fisher gerada foi a seguinte:

$f(x): 21,40726-0,41009 X_{1}-0,24855 X_{4}-0,28019 X_{5}$ - 0,00027 X $-0,00034 X_{7}-0,93471 X_{10}$

Esta função representa um índice que permite a classificação das áreas em parcialmente restauradas $(\mathrm{fd}(\mathrm{x})<0)$ ou não restauradas $(\mathrm{fd}(\mathrm{x})>0)$, quando se aplicam os valores das variáveis selecionadas e se adota como critério de floresta parcialmente restaurada aquela que apresentar $80 \%$ da pontuação.

Vale ressaltar que os reflorestamentos realizados em ambientes ciliares, selecionados para o presente estudo, com idades variando de um a 15 anos e que foram classificados como "parcialmente restaurados", demonstram que esses apresentam atributos que podem futuramente colaborar para o progresso da restauração da área, almejando atingir o estágio de equilíbrio dinâmico (steady state) (Engel \& Parrota, 2008). No entanto, não se deve desconsiderar que esses ambientes estão também sujeitos à ação de fatores bióticos (invasão por plantas daninhas, herbivoria, ausência de polinização) e mesmo fatores abióticos (mudanças na hidrologia e estrutura do solo) (Hobbs, 2007), que podem dificultar e eventualmente, cessar a trajetória da restauração.

As variáveis selecionadas pela função discriminante gerada estão entre os potenciais indicadores de restauração sugeridos por Moraes et al. (2010) como aqueles relacionados ao desenvolvimento de plantios de espécies arbóreas nativas (taxa de sobrevivência e desenvolvimento das mudas plantadas), parâmetros físico-químicos do solo (estrutura, fertilidade e teor de matéria orgânica), e mesmo dentre alguns dos atributos estruturais sugeridos como referência para monitoramento de projetos de restauração obtidos em matas ciliares na região de Floresta Estacional Semidecidual, tais como riqueza de espécies nos estratos arbóreos e regenerante; área basal e cobertura de copas (Suganuma et al., 2013). Essas estão também dentre os indicadores sugeridos para o protocolo de monitoramento de programas e projetos de restauração florestal (Pacto pela Restauração da Mata Altântica, 2013).

$\mathrm{O}$ número de espécies plantadas encontradas variou de 17 (Área 7A com $810 \mathrm{~m}^{2}$ ) a 38 (Área 10A com $2.652 \mathrm{~m}^{2}$ ). Mesmo com a intensidade amostral variável entre os reflorestamentos, os valores de riqueza de espécies encontrados no presente trabalho é semelhante aos valores de espécies plantadas (22 a 29 espécies em áreas amostrais de $500 \mathrm{~m}^{2}$ ) encontradas por Melo \& Durigan (2007) em reflorestamentos de restauração (com idades de 7, 9 e 13 anos) no Médio Vale do Paranapanema e dos números de espécies encontradas em reflorestamentos ciliares implantados no Estado de São Paulo nos últimos 50 anos, no qual Assis et al. (2013) observaram o aumento no número de espécies plantadas nos anos recentes, sendo o número médio de 25 espécies plantadas nas décadas de 1970, 1980 e 1990, e de 33 espécies plantadas no período entre 2000 e 2008.

Mesmo reconhecendo-se a importância dos reflorestamentos no sentido de acelerar o processo de sucessão secundária em áreas degradadas e em situações de ausência de remanescentes próximos (Guariguata \& Ostertag, 2001), a época da implantação desses corresponde à fase relatada por Rodrigues et al. (2007) como marcada pelo surgimento da ideia do aumento da diversidade de espécies e conservação da biodiversidade in situ. Esse fato resulta em poucas informações relativas às espécies de ocorrência regional com relação à época de coleta de sementes, produção de mudas e a disponibilidade dessas mudas nos viveiros da região, o que também justificam o reduzido número de espécies encontradas.

A mortalidade de individuos plantados e a densidade do estrato regenerante nas áreas com menor e maior riqueza de espécies foram de $50,5 \%$ e $42,2 \%$ e 15.500 e 4.895 ind.ha ${ }^{-1}$, respectivamente. No processo sucessional, a mortalidade pode ser consequência do autodesbaste da floresta, e com o surgimento de clareiras, novos indivíduos presentes no banco de sementes do solo e espécies alóctones ao reflorestamentos podem ser recrutados, compondo o estrato regenerante.

A seleção, pela análise discriminante, do atributo regeneração natural como indicador do processo de restauração pode estar relacionada às condições propícias criadas pelos reflorestamentos para o estabelecimento de plântulas através do favorecimento de microclima, fechamento do dossel (dependendo das espécies plantadas), melhorias na fertilidade do solo pela formação de camadas de serapilheira e húmus, atratividade a agentes dispersores e supressão de espécies invasoras (Engel \& Parrota, 2008; Viani et al., 2010). Outros trabalhos (Melo \& Durigan, 2007; Nobrega et al., 2008; Ferreira et al., 2010) também enfatizam a importância do estudo da regeneração natural como atributo indicador do progresso da sucessão e da autossustentabilidade de ecossistemas florestais (Daronco et al., 2013). 
Os valores de área basal em reflorestamentos sob processo de restauração podem indicar a incorporação de biomassa pelas espécies (Colmanetti \& Barbosa, 2013) sendo essa variável influenciada pela densidade de plantio (Machado et al., 2002) e também relacionada com a qualidade do sítio, já que são esperados maiores valores dessa variável em sítios com adequadas condições climáticas, edáficas e bióticas. Essas características somadas às densidades de plantio variáveis entre os reflorestamentos estudados, podem ter influenciado nos valores de área basal, favorecendo sua seleção como indicador da restauração. Em reflorestamentos ciliares avaliados por Melo \& Durigan (2007), as condições de elevada disponibilidade de luz (faixas ciliares de $30 \mathrm{~m}$ ), proximidade de cursos d'água e nutrientes (solos férteis) favoreceram a rápida evolução dessa variável, sendo essa uma característica fundamental para sua recomendação como indicador de monitoramento (Suganuma et al., 2013).

O acúmulo de serapilheira, outro atributo selecionado no presente trabalho como indicador da restauração é considerado também importante indicador da decomposição e ciclagem de nutrientes (Herrick et al., 2006) ao melhorar a fertilidade do solo, possibilitando o estabelecimento e futuro crescimento de espécies regenerantes sob o dossel da floresta (Engel \& Parrota, 2008). O emprego da serapilheira acumulada na avaliação de diferentes sistemas de restauração foi estudada por Sperandio et al. (2012), sendo que os valores de serapilheira acumulada no sistema consórcio entre eucalipto e acácias $\left(5,22 \mathrm{Mg} \cdot \mathrm{ha}^{-1}\right)$ e no sistema com espécies diversas $\left(5,67 \mathrm{Mg} \cdot \mathrm{ha}^{-1}\right)$, coletada na estação seca (junho) foram semelhantes aos valores de acúmulo da mata nativa $\left(5,96 \mathrm{Mg} \cdot \mathrm{ha}^{-1}\right)$.

Outra função química (indireta) da serapilheira é o enriquecimento da camada superficial do solo em matéria orgânica, a qual pode representar em torno de $70 \%$ da CTC. A capacidade de troca de cátions $(\mathrm{CTC}=\mathrm{K}+\mathrm{Ca}+\mathrm{Mg}+\mathrm{Al})$, variável também selecionada pela função discriminante gerada nesse estudo, é responsável pela magnitude da retenção e impedimento da lixiviação de cátions ao longo do perfil do solo, deixando-os próximos ao sistema radicular das plantas (Duarte \& Casagrande, 2006), o que favorece a absorção de nutrientes e o crescimento e desenvolvimento da vegetação. A CTC é também adotada como um dos parâmetros para a determinação da qualidade de solos florestais (Shoenholtz et al., 2000).
$\mathrm{Na}$ interpretação da classificação das parcelas dos reflorestamentos pela função discriminante gerada (Tabela 2), verifica-se, a partir dos oito anos, a predominância de parcelas classificadas como parcialmente restauradas, apresentando $80 \%$ da pontuação de um plantio de restauração considerado bem sucedido. A classificação de algumas parcelas nas áreas $15 \mathrm{~A}$ e $12 \mathrm{~A}$ como não restauradas pode ser devido à presença de clareiras que favoreceram o estabelecimento de gramíneas como o capim colonião (Panicum maximum), considerado um problema em reflorestamentos de restauração principalmente nos anos iniciais nos quais dificultam o estabelecimento da regeneração natural (Souza \& Batista, 2004).

Considerando-se o constante dinamismo em que se encontra a floresta, o monitoramento ideal dos reflorestamentos deveria ser por tempo ilimitado. No entanto, os entraves com relação à disponibilidade de recursos e tempo, bem como o grande número de áreas reflorestadas, tornam esta prática inexequível, sendo que o monitoramento de projetos de restauração raramente permanece por mais de cinco anos (Ruiz-Jaen \& Aide, 2005).

Com vistas à avaliação do sucesso do projeto de restauração, Gandolfi (2006) sugere o monitoramento de reflorestamentos ciliares por dois anos, para fiscalização do órgão competente (em casos de áreas autuadas), realizado em intervalos semestrais e considerando-se a recuperação no sentido da restauração estrutural e funcional o autor sugere o monitoramento por quatro anos, em intervalos semestrais.

No presente estudo, adotando-se a idade de oito anos como período de monitoramento, a frequência semestral de avaliação poderia ser adotada nos dois anos iniciais, seguida de avaliações anuais no período subsequente (seis anos), sendo que períodos mais longos trariam resultados mais próximos de uma área de referência mais representativa, uma vez que não foi usado como referência, uma área nativa próxima com pouco grau de alteração.

Esta função foi criada com base em valores médios das variáveis estruturais da vegetação e de solos em reflorestamentos ciliares localizados no entorno do reservatório da UHE de Volta Grande e em tributários do rio Grande, nos quais a metodologia de restauração baseou-se no plantio de mudas de diferentes grupos sucessionais. Mesmo com a crescente ideia de reflorestamentos fundamentados na ecologia da 
restauração, atualmente poucos são implantados com objetivos pré-estabelecidos de restauração e com variáveis definidas para futuros monitoramentos. $\mathrm{O}$ emprego da função obtida no presente trabalho em outras áreas sob processo de restauração poderia contribuir no sentido de gerar novos dados para a sua validação ou mesmo para a seleção de outros indicadores de monitoramento em reflorestamentos.

\section{Conclusões}

A função discriminante gerada (índice) permitiu a classificação de reflorestamentos realizados em ambientes ciliares, nos grupos previamente estabelecidos (parcialmente restaurados e não restaurados).

O número de espécies e área basal dos indivíduos plantados, o número de espécies e indivíduos regenerantes, o acúmulo de serapilheira e a CTC do solo podem ser consideradas variáveis importantes no monitoramento da restauração em reflorestamentos.

\section{Referências}

ALMEIDA, R. O. P. O.; SÁNCHEZ, L. E. Revegetação de áreas de mineração: critérios de monitoramento e avaliação de desempenho. Revista Árvore, Viçosa, MG, v. 29, n. 1, p. 47-54, 2005.

ANDERSEN, A. N.; SPARLING, G. P. Ants as indicators of restoration success: relationship with soil microbial biomass in the Australian seasonal tropics. Restoration Ecology, Malden, v. 5, n. 2, p. 109-114, 1997.

ANGIOSPERM PHYLOGENY GROUP. An update of the Angiosperm Phylogeny Group classification for the orders and families of flowering plants: APG III. Botanical Journal of the Linnean Society, v.161, p. 105-121, 2009.

ARONSON, J.; FlORET, C.; OVALlE, C.; PONTANIER, R. Restoration and rehabilitation of degraded ecosystems in arid and semi-arid lands: I. a view from the south. Restoration Ecology, Malden, v. 1, p. 8-17, 1993.

ASSiS, G. B.; SUGANUMA, M. S.; MELO, A. C. G. DE; DURIGAN, G. Uso de espécies nativas e exóticas no Estado de São Paulo (1957-2008). Revista Árvore, Viçosa, MG, v. 37, n. 4, p. 599609, 2013. DOI: 10.1590/S0100-67622013000400003

BOTELHO, S. A.; DAVIDE, A. C. Métodos silviculturais para recuperação de nascentes e recomposição de matas ciliares. In: SIMPÓSIO NACIONAL SOBRE RECUPERAÇÃO DE ÁREAS DEGRADADAS, 5., 2002, Belo Horizonte. Anais... Belo Horizonte: SOBRADE, 2002. p. 123-145.
BRANCALION, P. H. S.; GANDOLFI, S.; RODRIGUES, R. R. Incorporação do conceito da diversidade genética na restauração ecológica. In: RODRIGUES, R. R.; BRANCALION, P. H. S.; ISERNHAGEN, I. (Org.). Pacto para a restauração ecológica da Mata Atlântica: referencial dos conceitos e ações de restauração florestal. São Paulo: Instituto BioAtlântica, 2009. p. 37-54.

BRASIL. Ministério da Agricultura, Pecuária e Abastecimento. Lei n $^{0} 12.651$ de 25 de maio de 2012. Disponível em: <http://www. planalto.gov.br/ccivil 03/ ato2011-2014/2012/lei/112651.htm>. Acesso em: 03 nov. 2014. Publicado originalmente no Diário Oficial [da] República Federativa do Brasil, Brasília, DF, em 18 maio 2012a.

BRASIL. Ministério da Agricultura, Pecuária e Abastecimento. Lei n $^{0} \mathbf{1 2 . 7 2 7}$ de 17 de outubro de 2012. Disponível em: <http://www. planalto.gov.br/ccivil_03/_Ato2011-2014/2012/Lei/L12727.htm>. Acesso em: 06 nov. 2014. Publicado originalmente no Diário Oficial [da] República Federativa do Brasil, Brasília, DF, em 18 out. 2012 b.

CLAESSEN, M. E. C. (Org.). Manual de métodos de análise de solo. 2. ed. rev. atual. Rio de Janeiro: EMBRAPA-CNPS, 1997. 212 p. (EMBRAPA-CNPS. Documentos, 1).

COLMANETTI, M. A. A.; BARBOSA, L. M. Fitossociologia e estrutura do estrato arbóreo de um reflorestamento com espécies nativas em Mogi Guaçu, SP, Brasil. Hoehnea, São Paulo, v. 40, n. 5, p. 419-435, 2013. DOI: 10.1590/S2236-89062013000300003.

DARONCO, C.; MELO, A. C. G.; DURIGAN, G. Ecossistema em restauração versus ecosistema de referência: estudo de caso da comunidade vegetal de mata ciliar em região de Cerrado, Assis, SP, Brasil. Hoehnea, São Paulo, v. 40, n. 3, p. 485-498, 2013. DOI: 10.1590/S2236-89062013000300008

DUARTE, R. M. R.; CASAGRANDE, J. C. A. Interação solovegetação na recuperação de áreas degradadas. In: __ . Manual para recuperação de áreas degradadas do Estado de São Paulo com ênfase em matas ciliares do interior paulista. São Paulo: Instituto de Botânica, 2006. p. 52-63.

DURIGAN, G.; ENGEL, V. L.; TOREZAN, J. M.; MELO, A. C. G.; MARQUES, M. C. M.; MARTINS, S. V.; REIS, A.; SCARANO, F. R. Normas jurídicas para a restauração ecológica: uma barreira a mais a dificultar o êxito das iniciativas? Revista Árvore, Viçosa, MG, v. 34, n. 3, p. 471-485, 2010. DOI: 10.1590/S0100-67622010000300011

EHRENFELD, J. G. Defining the limits of restoration: the need for realistic goals. Restoration Ecology, Malden, v. 8, n. 1, p. 2-9, 2000.

ENGEL, V. L.; PARROTTA, J. A. Definindo a restauração ecológica: tendências e perspectivas mundiais. In: KAGEYAMA, P. Y; OLIVEIRA, R. E.; MORAES, L. F.; ENGEL, V. L.; GANDARA, F. B. (Org.). Restauração ecológica de ecossistemas naturais. Botucatu: FEPAF, 2008. p. 3-25.

FERREIRA, D. F. Estatística multivariada. Lavras: UFLA, 2008. $661 \mathrm{p}$.

FERREIRA, W. C.; BOTELHO, S. A.; DAVIDE, A. C.; FARIA, J. M. R.; FERREIRA, D. F. Regeneração natural como indicador de recuperação de área degradada a jusante da Usina Hidrelétrica de Camargos, MG. Revista Árvore, Viçosa, MG, v. 34, n. 4, p. 651660,2010 
GANDOLFI, S. Indicadores de avaliação e monitoramento de áreas em recuperação. In: WORKSHOP SOBRE RECUPERAÇÃO DE ÁREAS DEGRADADAS EM MATAS CILIARES, 2006, São Paulo. Anais... São Paulo: Instituto de Botânica, 2006. CD-ROM.

GUARIGUATA, M. R.; OSTERTAG, R. Neotropical secondary forest succession: changes in structural and funcional characteristics. Forest Ecology and Management, Amsterdam, v. 148, p. 185-206, 2001.

HERRICK, J. E.; SCHUMANB, G. E.; RANGO, A. Monitoring ecological processes for restoration projects. Journal for Nature Conservation, v. 14, p. 161-171, 2006.

HOBBS, R. J. Setting effective and realistic restoration goals: key directions for research. Restoration Ecology, Malden, v. 15, n. 2, p. 354-357, 2007.

IBGE. Manual técnico da vegetação brasileira. 2. ed. Rio de Janeiro, 2002. (Série Manuais Técnicos em Geociências, 1). Disponível em: <http://geoftp.ibge.gov.br/documentos/recursos naturais/manuais_tecnicos/manual_tecnico_vegetacao_brasileira. pdf $>$. Acesso em: 03 nov. 2014.

IBGE. Mapa de solos do Brasil. Rio de Janeiro: IBGE, 2001.

ISERNHAGEN, I.; BRANCALION, P. H. S.; RODRIGUES, R. R.; NAVE, A. G.; GANDOLFI, S. Diagnóstico ambiental das áreas a serem restauradas visando a definição de metodologias de restauração florestal. In: RODRIGUES, R. R.; BRANCALION, P. H. S.; ISERNHAGEN, I. (Org.). Pacto para a restauração ecológica da Mata Atlântica: referencial dos conceitos e ações de restauração florestal. São Paulo: Instituto BioAtlântica, 2009. p. 87-126.

LOMOV, B.; KEITH, D. A.; BRITTON, D. R.; HOCHULI, D. F. Are butterflies and moths useful indicators for restoration monitoring?: a pilot study in Sydney's cumberland plain woodland. Ecological Management \& Restoration, Carlton, v. 7, n. 3, p. 204-210, 2006.

MACHADO, S. A.; TONON, A. E. N.; FIGUEIREDO FILHO, A.; OLIVEIRA, E. B. Evolução da área basal e do volume em bracatingais nativos submetidos à diferentes densidades iniciais e em diferentes sítios. Floresta, Curitiba, v. 32, n. 1, p. 61-74, 2002.

MELO, A. C. G.; DURIGAN, G. Evolução estrutural de reflorestamentos de restauração de matas ciliares no Médio Vale do Paranapanema. Scientia Forestalis, Piracicaba, n. 73, p. 101-111, 2007.

MELO, A. C. G.; MIRANDA, D. L. C.; DURIGAN, G. Cobertura de copas como indicador de desenvolvimento estrutural de reflorestamentos de restauração de matas ciliares no Médio Vale do Paranapanema, SP, Brasil. Revista Árvore, Viçosa, MG, v. 31, n. 2 , p. 321-328, 2007. DOI: $10.1590 / \mathrm{S} 0100-67622007000200015$

MINGOTI, S.A. Análise de dados através de métodos de estatística multivariada: uma abordagem aplicada. Belo Horizonte: UFMG, 2007. 297 p.

MORAES, L. F. D.; CAMPEllo, E. F. C.; FRANCO, A. A. Restauração florestal: do diagnóstico de degradação ao uso de indicadores ecológicos para o monitoramento das ações. Oecologia Australis, v. 14, n. 2, p. 437-451, 2010. DOI: $10.4257 /$ oeco.2010.1402.07
NOBREGA, A. M. F.; VALERI, S. V.; PAULA, R. C.; SILVA, S. A. Regeneração natural em remanescentes florestais e áreas reflorestadas da várzea do rio Mogi- Guaçu, Luiz Antônio - SP. Revista Árvore, Viçosa, MG, v. 32, n. 5, p. 909-920, 2008. DOI: 10.1590/S010067622008000500016

PACTO PELA RESTAURAÇÃO DA MATA ATLÂNTICA. Protocolo para o monitoramento de programas e projetos de restauração florestal. 2013. Disponível em: <http://www. pactomataatlantica.org.br/pdf/ protocolo projetos restauracao.pdf $>$ Acesso em: 03 nov. 2014

POGGIANI, F.; STAPE, J. L.; GONÇALVES, J. L. M. Indicadores de sustentabilidade das plantações florestais. Série Técnica IPEF, Piracicaba, v. 12, n. 31,p. 33-44, 1998.

RODRIGUES, R. R.; GANDOLFI, S.; NAVE, A. G.; ATTANASIO, C. M. Atividades de adequação ambiental e restauração florestal do LERF/ESALQ/USP. Pesquisa Florestal Brasileira, Colombo, n. 55, p. 7-21, 2007.

RUIZ-JAÉN, M. C.; AIDE, T. M. Restoration success: how is it being measured? Restoration Ecology, Malden, v. 13, n. 3, p. 569577,2005

SAS INSTITUTE. SAS OnlineDoc: version 8. Cary, 1999.

SCHEEREN, L. W.; GEHRARTD, E. J.; FINGER, C. A. G.; LONGHI, S. J.; SCHNEIDER, P. R. Agrupamento de unidades amostrais de Araucaria angustifolia (Bert.) O. Ktze. Em função de variáveis do solo, da serapilheira e das acículas, na região de Canela, RS. Ciência Florestal, Santa Maria, RS, v. 10, n. 2, p. 39-57, 2000.

SCHOENHOLTZ, S. H.; MIEGROET, H.van.; BURGER, J. A. A review of chemical and physical properties as indicators of forest soil quality: challenges and opportunities. Forest Ecology and Management, Amsterdam, v. 138, p. 335-356, 2000.

SOCIETY FOR ECOLOGICAL RESTORATION. The SER international primer on ecological restoration. 2004. Disponível em: <http://www.ser.org $>$. Acesso em: 10 fev. 2014.

SOUZA, F. M.; BATISTA, J. L. F. Restoration of seasonal semideciduous forests in Brazil: influence of age and restoration design on forest structure. Forest Ecology and Management, Amsterdam, v. 191, p. 185-200, 2004

SPERANDIO, H. V.; CECÍLIO, R. A.; SILVA, V. H.; LEAL, G. F.; BRINATE, I. B.; CALDEIRA, M. V. W. Emprego da serapilheira acumulada na avaliação de sistemas de restuaração florestal em Alegre-ES. Floresta e Ambiente, Seropédica, v. 19, n. 4, p. 460467,2012

SUGANUMA, M. S.; ASSIS, B.; MELO, A. C. G.; DURIGAN, G. Ecossistemas de referência para restauração de matas ciliares: existem padrões de biodiversidade, estrutura florestal e atributos funcionais? Revista Árvore, Viçosa, MG, v. 37, n. 5, p. 835-847, 2013. DOI: $10.1590 / \mathrm{S} 0100-67622013000500006$

VIANI, R. A. G.; DURIGAN, G.; MELO, A. C. G. A regeneração natural sob plantações florestais: desertos verdes ou redutos de biodiversidade? Ciência Florestal, Santa Maria, RS, v. 30, n. 3, p. 533-552, 2010. 
